Paulo Luiz Farber

\title{
AVALIAÇÃO DA ATIVIDADE ELÉTRICA UTERINA EM RATAS WISTAR PRENHES E NÃO PRENHES INDUZIDA POR ELETROACUPUNTURA E DA INFLUÊNCIA DO SISTEMA NERVOSO CENTRAL E DOS CIRCUITOS ELÉTRICOS BIOLOGICAMENTE FECHADOS
}

Tese apresentada à Faculdade de Medicina da Universidade de São Paulo para obtenção do título de

Doutor em Medicina Área de concentração: Obstetrícia e Ginecologia Orientador: Prof. Dr. Marcelo Zugaib 


\section{FICHA CATALOGRÁFICA}

Preparada pela Biblioteca da

Faculdade de Medicina da Universidade de São Paulo

liarber, Paulo luiz

Avallnção da atividade clétrica uterina em ratas Wistar prenines e nāo preuhes Indiuzilı por cletroacupuntura e da influência do sistema nervoso central e dos Irculton elétricos biologicantente fechados / Paulo Luiz Farber. -- São Paulo, 1997.

T'ese(doutorado)-Faculdade de Medicina da Universidade de São Paulo.

1)epritumento de Obstetricia e Ginecologia.

hrua de concentração: Obstetricia e Ginecologia.

Orientador: Marcelo Zugaib.

1)escritores: 1.ELETROFISIOLOGIA'métodos 2.CONTRAÇÃO UTERINA/fisiologia I.]'RliNIII/. 4. ACUPUNTURA'métodos 5.ELETROACUPUNTURA/métodos 6.SISTJiMA NRIR VISU/Lesíes 7. VASOS SANGÜÍNEOS/fisiologia

IISI//M/SHIJ)-246/97 


\section{SUMÁRIO}
AGRADECIMENTOS
LISTA DE SIGLAS
RESUMO
SUMARY


2 - REVISÃO DA LITERATURA
3 - PROPOSIÇÃO 35
4 - MATERIAIS E MÉtOdOS _ 37
5 - RESULTADOS —u 48
6 - DISCUSSÃO
7 - CONCLUSÕES — 64
8 - REFERÊNCIAS BIBLIOGRÁFICAS $\quad 66$ 
AGRADECIMENTOS 
Ao Prof. Dr. Marcelo Zugaib, pelo pioneirismo e mentalidade científica, proporcionando o estudo da acupuntura na Clínica Obstétrica e pela orientação desta tese.

Ao Prof. Dr. César Timo-Iaria, por ter cedido seu laboratório para a realização dos experimentos e pelas valiosas sugestões no decorrer da tese.

Ao Dr. Wilson Carrara, pelo estímulo e pela orientação na primeira fase dos experimentos.

Ao Prof. Dr. Soubhi Kahhale pelo incentivo e ajuda enquanto chefe da Pós Graduação da Clínica Obstétrica.

Aos Drs. Mario Makoto Kondo e Edécio Armbruster pela ajuda e sugestões na forma final desta tese.

Ao Prof. Dr. Bjorn Nordenström pelas sugestões e pela doação de seu livro.

Ao Prof. Dr. Yoshiaki Omura pela oportunidade de apresentar este trabalho à especialistas durante os simpósios realizados em Nova Yorque em 1996 e 1997.

Aos meus colegas da Clínica Obstétrica pelo apoio às minhas pesquisas.

Aos meus colegas acupuntores, pelo incentivo.

À Sra. Mônica Inês Casajús de Domenech pelo auxílio nas dúvidas estatísticas.

À Sra. Regina Foltas pela revisão ortográfica.

À Energia Yang, na pessoa do Sr. Oscar Morais pelo empréstimo do Eletroestimulador e pelo apoio na realização desta tese.

Aos meus pais pelo estímulo à carreira científica.

À minha esposa Luciane pelo carinho, amor e paciência enquanto elaborava este trabalho. 
RESUMO 
O objetivo desse trabalho foi a avaliação da atividade elétrica uterina em ratas Wistar prenhes antes e após a eletroacupuntura e a influência do sistema nervoso central e dos circuitos elétricos biologicamente fechados. A avaliação da atividade elétrica cerebral e uterina foi realizada por meio de experimentos crônicos ( $\mathrm{n}=16,8$ prenhes e 8 não prenhes) e agudos $(\mathrm{n}=11,4$ prenhes e 7 não prenhes). As ratas prenhes receberam a eletroacupuntura nos pontos Sanyinjiao e Zusanli entre 17 a 19 semanas de prenhez. A fase de experimentos agudos consistiu de lesão na medula espinhal no nível de T1 (2 ratas, uma prenhe e a outra não), denervação do útero utilizando álcool absoluto (3 ratas, uma prenhe e duas não), eletroestimulação de artéria isolada do rabo (2 ratas não prenhes) e experimentos in vitro (4 ratas, duas prenhes e duas não). A atividade elétrica uterina de repouso foi semelhante nas ratas prenhes $(1,87+/-2,35$ eventos / 3 minutos $)$ e não prenhes $(2,31+/-1,57$ eventos / 3 minutos, $\mathrm{p}>0.1)$. Após a eletroacupuntura o número de eventos aumentou de 1,87 +/- 2,35 / 3 minutos para 28,06 +/- 17,27 / 3 minutos; $\mathrm{p}<0.01$. Verificou-se uma correlação entre o aumento da atividade elétrica cerebral (córtex e hipocampo) e da atividade uterina em 3 ratas (2 prenhes e 1 não prenhe). Nem lesões na medula espinhal, nem a denervação do útero nem a realização dos experimentos in vitro modificou o aumento da atividade uterina. A eletroestimulação da artéria isolada do rato alcançou o útero mas parou após o clampeamento da artéria. Portanto, a atividade elétrica uterina é semelhante nas ratas prenhes e não prenhes. A atividade elétrica uterina aumenta após 90 minutos de eletroacupuntura em ratas Wistar prenhes, provavelmente através dos circuitos elétricos biologicamente fechados. O sistema nervoso não é necessário para esse fenômeno. 


\section{FARBER, P. L. Evaluation of uterine electric activity in pregnant and non} pregnant Wistar rats induced by electroacupuncture and the influence of central nervous system and biologically closed electric circuits. São Paulo, 1997. Tese (Doutorado) - Faculdade de Medicina, Universidade de São Paulo. 84p.

The objective of this work was the evaluation of uterine electric activity in pregnant Wistar rats before and after electroacupuncture stimulation and the influence of central nervous system and biologically closed electric circuits on uterine electric activity. The evaluation of brain electric activity and uterine electric activity was studied by means of chronic experiments $(n=16,8$ pregnant and 8 non pregnant rats). In pregnant rats electroacupuncture was performed at acupoints Sanyinjiao and Zusanli between 17 and 19 days of pregnancy. The acute experiments phase was lesions in spinal cord at T1 level ( 2 rats, one pregnant and one non pregnant), denervation of uterus using absolute alcohol (3 rats, one pregnant and two non pregnant), electric stimulation of isolated tail artery (2 animals, non pregnant) and in vitro experiment (2 pregnant rats and 2 non pregnant rats). The uterine activity was similar in pregnant $(1,87+/-2,35$ events / 3 minutes $)$ and non pregnant rats $(2,31+/-1,57$ events / 3 minutes, $p>0.1)$. After electroacupuncture, the number of events rises for $1,87+/-2,35 / 3$ minutes to $28,06+/-17,27 / 3$ minutes; $\mathrm{p}<0.01$ (pregnant rats). In 3 rats ( 1 non-pregnant and 2 pregnants), was observed correlation between the rise of cerebral activity (cortex and hipoccampus) and the uterine activity. Neither lesions in spinal cord nor denervation of uterus and in vitro experiments modified the rising of uterine activity. The electric stimulation of isolated tail artery reached the uterus but stopped after clamping the artery. Therefere, the basal uterine electric activity is similar in pregnant and non pregnant Wistar rats; uterine activity rises after 90 minutes of electroacupuncture in Wistar pregnant rats, probably by biologically 
closed electric circuits and the nervous system is not necessary for this phenomenon. 
INTRODUÇÃO 
A acupuntura é uma ciência milenar chinesa, recentemente incorporada ao meio médico ocidental, inclusive sendo reconhecida como especialidade médica no nosso meio (CONSELHO FEDERAL DE MEDICINA, 1995). O tratamento consiste em aplicarmos um estímulo de natureza térmica (também conhecido como moxabustão), elétrica (eletroacupuntura), eletromagnética (magnetopuntura, acupuntura por microondas), pressão (acupressura), radiação laser (laserpuntura) ou inserção de agulhas em determinadas regiões do corpo conhecidas como pontos de acupuntura.

O estímulo provocado pela introdução de agulhas sem a utilização de eletricidade parece estar relacionado com o estímulo elétrico, provocado pela diferença de temperatura entre os dois metais que compõem a agulha (em geral o cabo da agulha é de cobre, latão, prata ou ouro enquanto que o corpo é de aço inoxidável) (ZANELLA, 1989), podendo colaborar também a temperatura da pessoa que estiver portando a agulha ao introduzi-la, o que é conhecido como efeito Seebeck (COHEN et al., 1997). Outra possibilidade é a agulha servir de entrada para ondas e campos eletromagnéticos de baixa frequiência (em torno de $30-50 \mathrm{~Hz}$ ), que transitam para a ionosfera e voltam para a crostra terrestre e de novo para a ionosfera, fato conhecido como ressonância de Schumann, pois as freqüências 
detectadas no ponto de acupuntura Quchi (IG 11) são semelhantes à ressonância de Shumann (COHEN, $1997^{1}$ ).

A eletroacupuntura é a modalidade de estímulo mais estudada, e o estímulo analgésico consiste de uma estimulação nervosa periférica com o objetivo de acessarmos o sistema nervoso central (SNC), por meio de uma via aferente através do trato anterolateral contralateral da medula espinhal, núcleo magno da rafe e formação reticular, atingindo diversas áreas do sistema nervoso central, incluindo diversas secções do hipotálamo, tálamo, hipocampo, áreas septais e hipófise (FARBER; TIMO-IARIA, 1994).

Mas o sistema nervoso não é a única via carregadora de energia (elétrica e eletromagnética) nos organismos vivos. Segundo NORDENSTRÖM (1994), nós possuímos circuitos elétricos fechados, onde a fiação é substituída por condução iônica, conhecidos por Circuitos Elétricos Biologicamente Fechados (CEBF). O primeiro sistema de CEBF identificado foi o Circuito Fechado Vascular (CFV). A parede vascular possui uma resistência elétrica 150-200 vezes maior que a do plasma. Os vasos sanguiíneos, portanto, podem funcionar como cabos relativamente isolados para o transporte de íons.

Embora a maioria das pesquisas referentes à acupuntura baseiem-se em seu mecanismo analgésico, outras alterações podem ser provocadas após o estímulo.

\footnotetext{
${ }^{1}$ COHEN, M. Shared frrequency components between Schumann resonances, ECG spectra and acupuncture. Trabalho apresentado no 13th Annual International Symposium on Acupuncture and Electro-therapeutics, Columbia University, October 23-26, New York, USA, 1997.
} 
Dentre as funções fisiológicas provocadas pela acupuntura está a indução do trabalho de parto. KUBISTA et al. (1975) observaram o desencadeamento de contrações uterinas após a eletroacupuntura em gestações próximas ao termo. A partir dessa publicação, outros autores demonstraram que não só era possível reproduzir os resultados de KUBISTA como também desencadear o trabalho de parto (YIP et al., 1976, TSUEI et al., 1977, ZHU et al., 1986).

Pesquisas realizadas na Clínica Obstétrica do HC-FMUSP comprovaram que a estimulação elétrica sobre pontos de acupuntura foi capaz de induzir as contrações uterinas e o trabalho de parto em $75 \%$ das gestantes que apresentavam maturidade de colo uterino (FARBER et al., 1994).

Embora esteja estabelecido o fato de que o estímulo elétrico no ponto de acupuntura provoca um aumento da atividade uterina em humanos, não foram encontradas referências quanto a nenhum modelo experimental que pudesse ser utilizado para estudar com maior profundidade esse fenômeno. Outro fato sobremaneira motivador foi o completo desconhecimento sobre os mecanismos de ação da acupuntura sobre as contrações uterinas. 
LITERATURA 


\section{$\underline{\text { A Acupuntura e o Sistema Nervoso }}$}

\section{O Ponto de Acupuntura}

Em 1959, chineses do Departamento de Anatomia Humana da Universidade de Shanghai realizaram preparações histológicas da região, abrangendo 324 pontos de acupuntura clássicos, e demonstraram que em 323 deles encontravam-se terminações nervosas a $5 \mathrm{~mm}$ de seu interior (CAI, 1992). FLECK (1975), estudando potenciais de ação provocados por estímulo do ponto de acupuntura e diretamente no nervo mediano (registrados em unidades múltiplas) demonstrou que eles eram idênticos. HYVARINEN e KARLSON (1977) demonstraram que os pontos de acupuntura eram regiões da pele cuja resistência elétrica era baixa. CISZEK et al. (1985) encontraram nesses pontos de baixa resistência elétrica concentração de terminações nervosas livres maior que na periferia, e HEINE (1988) revelou que desses pontos saíam fibras nervosas em direção à fáscia corporal superficial ou para a camada músculo-aponeurótica. TAKESHIGE et al. (1993) demonstraram que, estimulando-se um ponto de acupuntura através da pele ou diretamente o nervo correspondente, os potenciais evocados no sistema nervoso central (SNC) eram idênticos. 
Esses fatos permitem admitir que um ponto de acupuntura é uma região da pele em que é grande a concentração de terminações sensoriais e que sua estimulação possibilita acesso direto ao SNC.

\section{A Via Aferente da Acupuntura}

Desde 1975 muitos trabalhos vêem mostrando que os efeitos analgésicos da acupuntura são intermediados pelo SNC. Diversos pesquisadores chineses e ocidentais descobriram que a acupuntura provoca em diversas regiões do SNC potenciais evocados, bem como aumento da atividade de neurônios unitários e multiunitários (FLECK, 1975, LEVY; MATSUMOTO, 1975, TODA; IRIKI, 1979, ZHENGQIU et al., 1986, JIANREN et al., 1987, TAKESHIGE, 1993). Embora as vias nervosas implicadas na acupuntura já estejam razoavelmente bem definidas, a maior parte dos seus efeitos terapêuticos ainda não foram convenientemente explicados. O envolvimento dos núcleos nervosos que intervêem nos efeitos da acupuntura está sendo melhor esclarecido (LEE; BEITZ, 1992, 1993) pela utilização da imunorreatividade da proteína c-Fos; esses estudos corroboram a maioria dos trabalhos publicados, mas por outro lado criam novos pontos de interrogação a serem desvendados.

As vias da acupuntura diferem segundo o estímulo das terminações nervosas seja de baixa $(1-15 \mathrm{~Hz}$ ) ou alta (mais de $100 \mathrm{~Hz}$ ) freqüência. 
Como a maioria das terapias por acupuntura utiliza baixa frequiência, vamos ater-nos a esse tipo de estímulo.

O estímulo elétrico de baixa freqüência aplicado no nervo (ponto de acupuntura) provoca impulsos que ascendem ao SNC pelo cordão anterolateral contralateral da medula espinhal (SATO et al., 1991), núcleo reticulogigantocelular da formação reticular e núcleo magno da rafe (TAKESHIGE et al., 1992) até a região dorsal do estrato cinzento periaquedutal do mesencéfalo (WANG et al., 1990; TAKESHIGE et al., 1992; TAKESHIGE et al., 1993) em sua região dorsal. Esse é o ponto de partida para o que se considera a via aferente da acupuntura. O estudo eletrofisiológico dos núcleos centrais implicados na acupuntura revela as características eletrofisiológicas mencionadas abaixo.

1) Potenciais de ação evocados pela eletroestimulação de baixa freqüência $(1 \mathrm{a} 4 \mathrm{~Hz})$ do ponto de acupuntura ou após injeção intraperitoneal de morfina na dose de $0,5 \mathrm{mg} / \mathrm{kg}$.

2) A eletroestimulação direta dos núcleos centrais com a freqüência de $80 \mathrm{~Hz}$ produz analgesia semelhante à da acupuntura, i.e., com tempo de analgesia que se prolonga após o término do estímulo. Há diferenças individuais nessa resposta ao estímulo (há animais que respondem com analgesia e animais que não). A hipofisectomia bloqueia essa analgesia e a injeção intraperitoneal de Naloxone ou de anti-soro de beta-endorfina no $3^{\underline{0}}$ ventrículo também bloqueia o efeito desses estímulos. 
3) A estimulação elétrica dos núcleos centrais evoca potenciais de campo ao longo das projeções rostrais da via correspondente.

4) A lesão dos núcleos mencionados bloqueia a analgesia produzida por acupuntura ou por estímulo dos núcleos caudais.

Do estrato cinzento periaquedutal dorsal a via aferente implicada nos efeitos da acupuntura dirige-se ao hipotálamo anterior, hipotálamo posterior e núcleo centro-mediano do tálamo (região medial). Do hipotálamo posterior, partes dessa via ascendem aos núcleos septais laterais, fascículo do cíngulo, hipocampo dorsal e trato habênulo-interpeduncular. Da região medial do núcleo centro-mediano há contingentes que ascendem ao hipocampo dorsal. Do hipotálamo lateral, alguns ramos dirigem-se aos núcleos septais laterais enquanto outros ativam a eminência média (que faz parte do sistema liberador de beta-endorfinas, veja adiante). Uma via liga os núcleos septais laterais ao trato habênulo-interpeduncular (TAKESHIGE et al., 1993).

Como se vê, a via aferente da acupuntura se abre em vias divergentes adiante do estrato cinzento periaquedutal dorsal e convergentes para o trato habênulo-interpeduncular; daí, as informações seguem para o hipotálamo anterior e deste para a região medial do núcleo arqueado hipotalâmico, onde a via termina (WANG et al., 1990a, WANG et al., 1990b, TAKESHIGE et al., 1993).

\section{Vias de Liberação de Beta-endorfinas}


Desde a descoberta das beta-endorfinas por HUGHES et al. (1975), diversos pesquisadores mostraram que há aumento de beta-endorfinas no líquido cefalorraquidiano durante a estimulação de pontos de acupuntura; demonstrou-se também que a analgesia provocada pela acupuntura de baixa frequiência é parcialmente abolida por Naloxone, antagonista das endorfinas, ou por microinjecão de anti-soro de beta-endorfina no terceiro ventrículo (SJOLUND et al., 1977, POMERANZ; WARMA, 1979, SODIPO et al., 1981, TAKESHIGE et al., 1991a, TAKESHIGE et al., 1991b, TAKESHIGE et al., 1993). Por intermédio de dois centros da via aferente, o hipotálamo lateral e o núcleo arqueado hipotalâmico medial, são ativadas a área préóptica e a eminência média. $\mathrm{O}$ estímulo direto dessas áreas não provoca analgesia (TAKESHIGE et al., 1991a). A eminência média ativa a liberação de beta-endorfinas pela hipófise. As beta-endorfinas atuam facilitando présinapticamente as vias entre as regiões medial e posterior do núcleo arqueado hipotalâmico, o que é intermediado por dopamina (TAKESHIGE et al., 1991a, TAKESHIGE et al., 1991b)

\section{Via Eferente}

A partir da região posterior do núcleo arqueado hipotalâmico, o estímulo da acupuntura ativa o sistema descendente inibidor da dor. Demonstrou-se que:

1) a eletroestimulação de baixa frequiência (1 a $4 \mathrm{~Hz})$ do ponto de acupuntura ou a injeção intraperitoneal de morfina na 
dose de $0,5 \mathrm{mg} / \mathrm{kg}$ ativam neurônios do sistema descendente inibidor da dor;

2) a eletroestimulação direta dos núcleos que fazem parte desse sistema inibidor com freqüência de $80 \mathrm{~Hz}$ provoca analgesia, cujo tempo, distintamente do que ocorre com os núcleos da via aferente, não se prolonga após o término do estímulo, e cujas diferenças individuais inexistem (todos os animais respondem com o mesmo grau), e tampouco é afetada pela hipofisectomia, nem por injeção intraperitoneal de Naloxone ou de anti-soro de beta-endorfina no terceiro ventrículo;

3) o estímulo elétrico dos núcleos do sistema inibidor evoca potenciais em núcleos rostrais da via;

4) a lesão desses núcleos bloqueia tanto a analgesia produzida por acupuntura como a causada por estímulo dos núcleos caudais.

A via que se inicia na porção posterior do núcleo arqueado hipotalâmico desce para o núcleo ventromediano do hipotálamo, por uma via mediada pela dopamina. A partir daí, essa via eferente divide-se em noradrenérgica, que desce para o núcleo reticuloparagigantocelular e provavelmente também para o núcleo reticulogigantocelular, e serotoninérgica, que desce pelo estrato cinzento periaquedutal (região ventral) e pelo núcleo magno da rafe; as duas vias terminam no funículo 
dorsolateral da medula espinhal, onde exercem seu efeito inibidor (TAKESHIGE et al., 1992).

\section{Identificação da Expressão da Proteína c-Fos}

A proteína fos celular (c-Fos) é um oncogene e está presente no núcleo de muitas células. Quando expressa, ela interage com o DNA para regular a transcrição de outros genes. Estímulos nocivos, visuais, auditivos, vestibulares e outros induzem a ativação da c-Fos em centros específicos do SNC, o que é detectado por imunorreatividade contra c-Fos nos neurônios de 20 a 90 minutos após o estímulo (LEE; BEITZ,1992, 1993).

LEE; BEITZ (1992) comprovaram que a expressão da c-Fos no corno posterior da medula espinhal, provocada por estímulo nocivo, era suprimida por acupuntura de alta ou baixa freqüência. Em 1993 os mesmos autores passaram a pesquisar os núcleos do SNC, onde era identificada a expressão da c-Fos após o estímulo de baixa e alta frequiência nos pontos de acupuntura (LEE; BEITZ, 1993). É importante salientar que determinadas populações neuronais têm expressão da c-Fos constitucional, incluindo o córtex cerebral, estruturas límbicas e sistema auditivo, enquanto outros grupos neuronais não a expressam (LEE; BEITZ, 1993). Embora não se tenha realizado estudo sistêmico de todos os neurônios de nenhuma espécie, por motivos óbvios, demonstrou-se a ativação da c-Fos na acupuntura de baixa freqüência $(4 \mathrm{~Hz})$ e alta freqüência $(100 \mathrm{~Hz})$ nas seguintes estruturas:

1) baixa freqüência: 
- lâminas I e II do corno posterior da medula espinhal (altura da L2);

- núcleo reticular lateral;

- núcleo pálido da rafe;

- núcleo magno da rafe;

- núcleo ventromediano;

- loco cerúleo;

- substância negra (compacta);

- núcleo pretectal posterior;

- núcleo parabraquial lateral;

- núcleo habenular medial e lateral;

- núcleo arqueado hipotalâmico;

- núcleo dorsal da rafe (caudal e posterior);

- núcleo cuneiforme;

- estrato cinzento periaquedutal (todas as subdivisões);

* Não exprimiram c-Fos: núcleos motores ou proprioceptivos, incluindo o corno ventral da medula espinhal, núcleo grácil e o núcleo rubro.

2) alta freqüência:

- lâminas I e II do corno posterior da medula espinhal (altura da L2);

- núcleo reticular caudoventrolateral;

- núcleo pálido da rafe;

- loco cerúleo;

- substância negra; 
- núcleo pretectal posterior;

- núcleo parabraquial lateral;

- núcleo dorsal da rafe (caudal e posterior);

- estrato cinzento periaquedutal (látero-ventral).

Como indicam as relações acima mencionadas, determinadas estruturas neuronais são ativadas somente com estímulo de baixa freqüência (núcleos cuneiforme, habenular, arqueado e ventromediano, e o restante do estrato cinzento periaquedutal). A ativação de outras estruturas, que não correspondem à via reconhecida como implicada na acupuntura, leva a crer que a rede neuronal envolvida é muito mais complexa que a atualmente admitida (núcleo reticular lateral, núcleo pálido da rafe, loco cerúleo, substância negra, núcleo pretectal posterior, núcleo parabraquial lateral, núcleos habenulares medial e lateral, núcleo dorsal da rafe caudal e posterior e núcleo cuneiforme, embora muitos deles já tenham sido identificados como parte da via central da acupuntura (TODA; IRIKI, 1979, JIANREN et al., 1987).

\section{Neuromoduladores}

Embora a pesquisa sobre neurotransmissores seja válida, como explicar a ação prolongada da acupuntura sendo que estes têm meia-vida curta? A resposta está nos neuromoduladores, em especial o neuropeptídeo Y. BUCINSKAITE et al. (1994) descobriram que a eletroacupuntura provocava um aumento de neuropeptídeo Y no hipocampo, córtex occipital, corpo estriado e hipófise, sendo que havia um aumento concomitante na 
neurocinina A e substância $\mathrm{P}$, com exceção do córtex occipital. $\mathrm{O}$ neuropeptídeo Y é um neuromodulador, não um neurotransmissor. Dentre suas ações, inibe a substância $\mathrm{P}$ e a acetilcolina em cultura de neurônios. Atua nos canais de cálcio, sendo que sua ação vai variar conforme a concentração intracelular de cálcio, aumentando a permeabilidade ao cálcio quando a concentração estiver baixa e fechando os canais quando alta. Paradoxalmente, o neuropeptídeo Y inibe a secreção de noradrenalina dos terminais simpáticos e aumenta os efeitos pós-sinapticamente, além de reduzir a excitação sináptica das células piramidais nas áreas CA1 e CA3 hipocampais (COLMERS; BLEAKMAN, 1994). Na modulação do sistema endócrino, aumenta a resposta do LH e FSH ao LH-Rh em ratos, mas essa ação facilitatória é restrita ao proestro (fase pré-ovulatória), não se observando em outras fases (BAUER-DANTOIN et al., 1993). BUCINSKAITE et al. (1996) demonstrou aumento de neuropeptídeo Y, neurocinina A e substância $\mathrm{P}$ no hipocampo, em ratos Wistar e SHR (hipertensos espontaneamente), aliados a uma diminuição da atividade em campo aberto, sugerindo que seja uma das razões do efeito antidepressivo da acupuntura.

\section{Sistemas opióides e antiopióides}

Outra linha de pesquisa interessante que vem se desenvolvendo nos últimos anos é a tentativa de se potencializar a acupuntura por meio de inibidores das peptidases, que aumentariam a ação da acupuntura pela diminuição da metabolização das encefalinas. KISHIOKA et al. (1994) tentaram administrar um coquetel dessas substâncias, mas o interessante é 
que a analgesia, eletroacupuntura de baixa freqüência, não foi potencializada (foi até atenuada) por um conjunto de inibidores das peptidases (Amastatina, Captopril e Fosforamidon), embora os inibidores das peptidases potencializassem os efeitos analgésicos das encefalinas. Os autores concluem que a eletroacupuntura provavelmente ativa um sistema de peptídeos antiopióides.

A colecistocinina octapeptídeo (CCK-8) é um dos antiopióides mais conhecidos. O uso dessas substâncias abole totalmente a analgesia por morfina em ratos, mediado por receptores CCK-B. ZHOU et al. (1993) experimentaram utilizar o L-365,260 - um antagonista CCK-B, e verificaram que ele potencializa a analgesia por eletroacupuntura, mas dependendo da freqüência ocorrem graus diferentes de potencialização: EAC $100 \mathrm{~Hz}>15 \mathrm{~Hz}>2 \mathrm{~Hz}$, ou seja, quanto maior a freqüência maior a participação desses antiopióides na acupuntura.

Esses trabalhos vêm demonstrar que a acupuntura é um modulador do SNC, agindo principalmente estimulando a harmonia, e não excitando ou deprimindo.

Os Circuitos Elétricos Biologicamente Fechados (CEBF)

O estudo dos CEBF iniciou-se no final da década de 50 quando NORDENSTRÖM, analizando radiografias de câncer do pulmão, notou que algumas delas apresentavam uma coroa, que não podia ser explicada. Essa estrutura peculiar pôde ser encontrada em cerca de 20 a 30\% das 
radiografias de neoplasias malignas pulmonares, principalmente na visão oblíqua (NORDENSTRÖM, 1983).

A zona mais próxima ao tumor foi chamada de zona "A", vista radiologicamente como um halo ou arco translúcido ao redor de todo ou parte do parênquima pulmonar infiltrado. A zona A pode ser encontrada também em tumores benignos e reações inflamatórias (NORDENSTRÖM, 1983).

A seguir, circundando a zona "A", encontramos a zona "B", constituída de "arcos" e "arcadas", linhas de alta radiopacificidade, na periferia da zona "A“. Outras estruturas relativamente radiopacas encontradas são as lamelas e infiltrações radiais (NORDENSTRÖM, 1983).

Esses achados levaram NORDENSTRÖM a estudar a possibilidade de polarização eletroquímica entre o núcleo tumoral e o tecido adjacente. Foram realizados estudos de potencial elétrico do pulmão e pleura em 27 cães e 119 pacientes, que obtiveram os seguintes resultados:

- repetidas inserções e retiradas do eletrodo exploratório revelaram um padrão especial de potencial, um "perfil potencial do tecido", usualmente reprodutível para cada lesão;

- tumores malignos de tamanho, localização e tipo histológico semelhantes podem apresentar padrões completamente diferentes de potencial elétrico; 
- regiões de tecido lesado mostraram potenciais locais negativo ou positivo em comparação com o tecido pulmonar adjacente;

- potenciais de superfície negativos e potenciais internos elevados também foram encontrados em tumores malignos e processos infecciosos locais;

- um potencial de superfície positivo e negativo internos também foram encontrados nos granulomas (como na tuberculose);

- tumores malignos e lesões inflamatórias apresentaram em grande parte dos casos tipos similares de perfil de potencial elétrico, com diferenças individuais (NORDENSTRÖM, 1983).

Esses achados levaram NORDENSTRÖM a pesquisar largamente os potenciais dos tecidos normais e doentes. A conclusão foi que as atividades metabólicas do pulmão, assim como do estômago, do fígado e provavelmente de muitos outros tecidos, podem apresentar ondas de lenta mudança de potencial (NORDENSTRÖM, 1983). Posteriormente, LIBOFF $(1997)^{2}$ demonstrou que as proteínas insaturadas contêm uma carga extra que passa de uma proteína para outra em ondas durante o metabolismo, corroborando com os achados de NORDENSTRÖM. Porém, quando ocorre uma lesão local no órgão, aparece um acúmulo local de cargas ("potencial de lesão", por difusão dos produtos iônicos da decomposição). Um potencial é então criado entre o tecido lesado e o adjacente saudável, de onde, na opinião de NORDENSTRÖM, provém a energia para a cura da lesão. A lesão inicialmente é sempre eletropositiva em relação ao sangue, 
ocorrendo uma flutuação entre positiva e negativa em relação ao sangue, com ânions e cátions movendo-se para dentro e fora da lesão dentro dos Circuitos Elétricos Vaso Intersticiais (CEVI). Quando a diferença de potencial voltar a zero, a lesão deverá estar curada (NORDENSTRÖM, 1994).

O estudo dos potenciais elétricos e do transporte de íons através da corrente elétrica (eletroosmose) levou NORDENSTRÖM a formular uma teoria completamente diferente no que se refere ao nosso sistema circulatório. Dentro dessa visão, além do transporte de sangue, gases e nutrientes, os nossos vasos teriam função de transporte iônico, onde a força para esse transporte viria dos potenciais elétricos.

Os CEBF vasculares dividem-se em CFV e CEVI (o sistema nervoso também é um tipo particular de CEBF). A superfície da íntima dos vasos é composta parcialmente de mucopolissacárides contendo grupos sulfatos e carboxilatos. Essa estrutura química fornece à íntima, comparando-se com o sangue, um potencial de rede de -3 a $-13 \mathrm{mV}$. Essa superfície interna negativa repele plaquetas, eritrócitos e outros corpúsculos sangüíneos, que são carregados negativamente. Qualquer lesão da íntima vai deixá-la carregada positivamente, induzindo trombose local (NORDENSTRÖM, 1983).

As paredes das veias e artérias possuem resistência elétrica cerca de 150 a 200 vezes maior que a do meio condutor do sangue, o plasma. Os vasos sangüíneos, portanto, podem funcionar como "cabos" condutores de

\footnotetext{
${ }^{2}$ LIBOFF, A. Electromagnetic basis for life: Effects of electromagnetic fields on biological system, behavior and evolution. Trabalho
} 
íons. Uma forma de movimentar esses íons seria através de um campo magnético movente externo, já que os vasos sangüíneos formam alças, facilitando a interação entre o campo magnético externo e o CFV (NORDENSTRÖM, 1994).

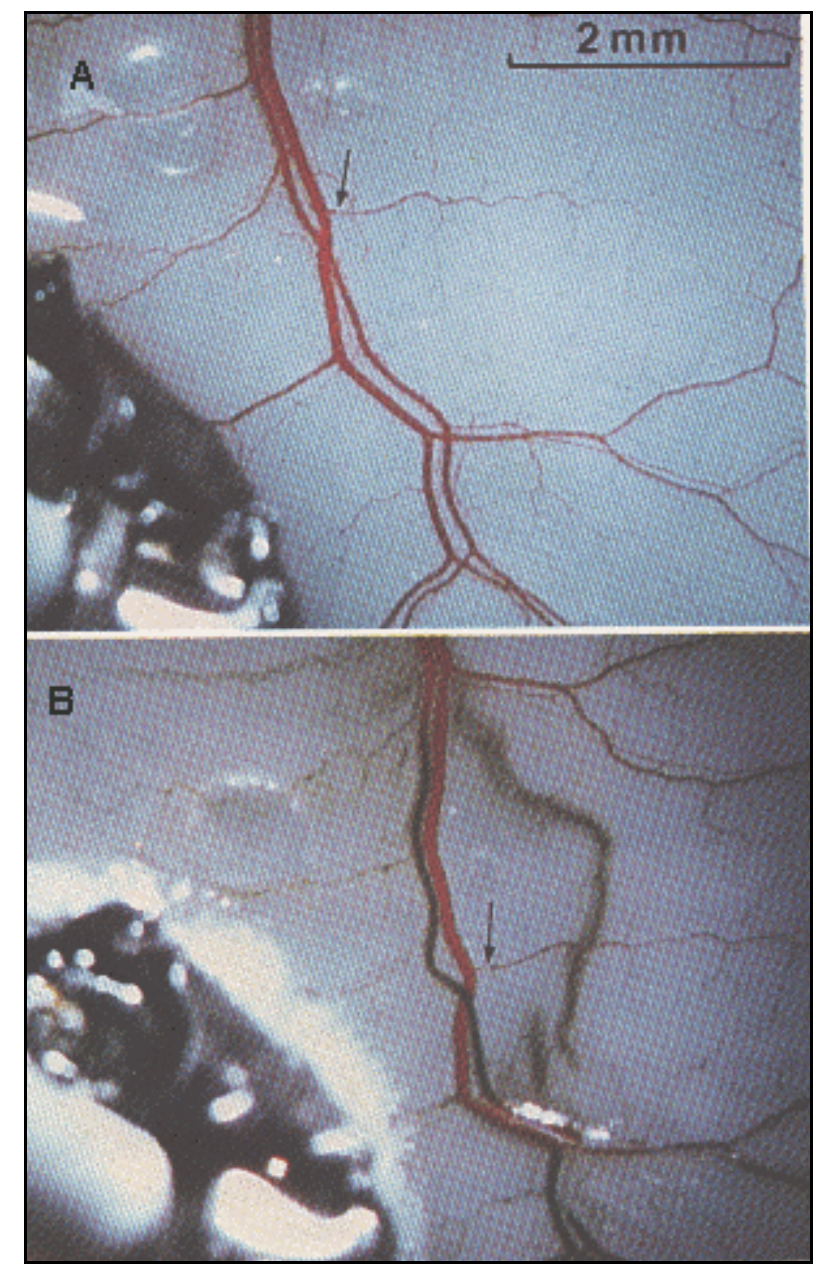

FIGURA 1. Efeitos intra-arteriais da passagem de corrente direta entre a artéria e o mesentério de cão. $O$ eletrodo aórtico é o catodo enquanto que o do mesentério é o anodo, visível no canto inferior esquerdo das figuras. (A) Antes da passagem da corrente. $O$ vaso maior é uma veia e o vaso adjacente, uma artéria. Um pequeno ramo da veia está bloqueado (seta). (B) Após a passagem da corrente. A artéria trombosou e ficou marrom. Eventualmente a veia mostra alguma descoloração. O ramo bloqueado não sofreu nenhuma transformação. Conseqüentemente, podemos inferir que a corrente elétrica flui preferencialmente através da artéria, que corresponde ao principal canal de comunicação entre os eletrodos (reproduzido de NORDENSTRÖM, 1983). 
Dentre os experimentos feitos para provar a existência dos CEBF, um dos mais interessantes é o da Figura 1. Quando passamos uma corrente elétrica galvânica entre a aorta e o mesentério, o fluxo é tão intenso que trombosa a artéria. Isso prova que nos organismos vivos a corrente elétrica tem preferência por circuitos elétricos fechados.

Em resumo, os organismos vivos possuem uma rede de transmissão de corrente elétrica e eletromagnética, podendo ser formada por nossas veias e principalmente artérias (CFV) ou os capilares e interstícios (CEVI).

\section{Contrações Uterinas}

O útero pertence ao grupo de músculos lisos espontaneamente ativos, ou seja, um pedaço de útero isolado, grávido ou não, apresenta contrações espontâneas regulares, sem qualquer estímulo nervoso ou hormonal (WRAY, 1993). O registro eletromiográfico das contrações uterinas é um bom parâmetro para a avaliação da atividade uterina, pois mostra que as contrações espontâneas são precedidas por potenciais de ação, e os agonistas podem alterar a intensidade das contrações agindo na duração dos trens e na frequência de potenciais de ação (WRAY, 1993).

A base desse mecanismo miogênico é a despolarização espontânea das células marca-passo no miométrio. Ao contrário do músculo cardíaco, as células marca-passo miometriais não são anatomicamente definidas (WRAY, 1993). Desconhecemos o porquê de um grupo de células tornar-se marca-passo, ou mesmo a troca iônica realizada nas mesmas (Figura 2). 


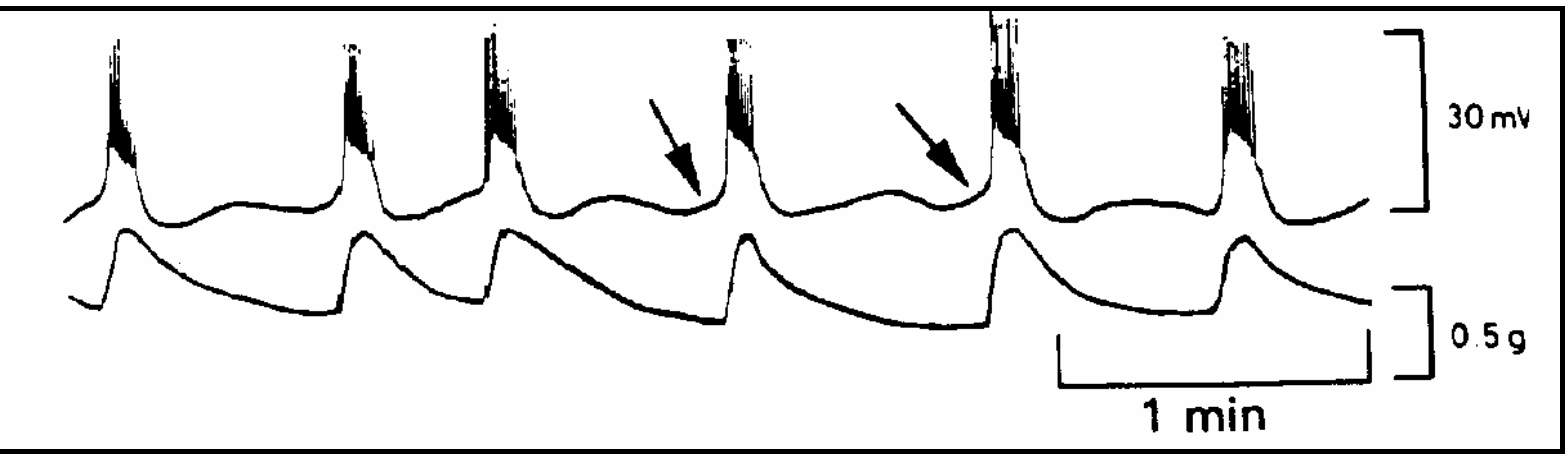

FIGURA 2. Potencial de membrana (superior) e contrações uterinas (inferior) registradas simultanemente no miométrio circular no $31^{\underline{0}}$ dia de prenhez em cobaios. Potenciais das células marca-passo são indicados por setas (PARKINGTON; COLEMAN, 1990 apud WRAY, 1993).

O músculo liso apresenta potenciais de membrana e de ação semelhantes às fibras musculares esqueléticas. Entretanto, no estado normal de repouso, o potencial de membrana é, em geral, da ordem de $\quad-50$ a -60 $\mathrm{mV}$, ou seja, $35 \mathrm{mV}$ menos negativo que no esquelético (GUYTON, 1988).

O tamanho e a forma do potencial de ação depende da idade gestacional e da espécie, podendo variar de uma espícula a um platô. Em geral, o desencadeamento do potencial de ação é devido predominantemente à entrada de íon cálcio e sua repolarização pela inativação dos canais de cálcio e efluxo de potássio (WRAY, 1993).

No miométrio, o íon cálcio $\left(\mathrm{Ca}^{2+}\right)$ é o maior segundo mensageiro intracelular. Pela regulação dos níveis intracelulares de íon cálcio, as células musculares contraem ou relaxam. Um aumento de $10^{-7}$ para $10^{-5}$ molar na 
concentração intracelular é necessário para produzir contração pela interação dos miofilamentos (KAMM; STULL, 1989).

\section{Estimulação da Entrada do Íon Cálcio pelos Agonistas}

O potencial de membrana do músculo liso freqüentemente apresenta comportamento oscilatório, com picos de íon cálcio superpostos a picos de despolarização. Muitos mecanismos podem estar envolvidos. Tem sido proposto que, nas oscilações induzidas pelos agonistas, o íon cálcio entra através dos canais de cálcio voltagem dependentes (VGC), aumentando a própria concentração intracelular e ativando os canais de potássio que se abrem e hiperpolarizam a membrana celular. O potencial de membrana é então menor do que o limiar para abrir os VGC, que se fecham, e a concentração intracelular de íon cálcio cai abaixo dos níveis de ativação dos canais de potássio (VAN BREEMEN; SAIDA, 1989).

Os conceitos das relações agonista-receptor, geração de segundo mensageiros e regulação de síntese de proteínas específicas tiveram avanços significativos na atualidade. De interesse particular é a expressão de importantes proteínas e o potencial controle dos processos genéticos na regulação do parto. Resumidamente, o DNA especifica os tipos de proteínas sintetizadas pelas células, com o RNA mensageiro (mRNA) funcionando como uma forma para a síntese protéica. O processo de transcrição seguido pela translação permite a síntese de proteínas específicas por meio do código do mRNA. O fluxo de informação genética na célula muscular lisa, 
assim como nas outras células, segue esse procedimento (TABB; GARFIELD, 1992).

Os agonistas são também responsáveis pela geração de mensageiros intracelulares ao lado do íon cálcio. Os nucleotídeos AMP cíclico (AMPc) e GMP Cíclico (GMPc) estimulam as Ca-ATPases na membrana celular e no retículo sarcoplasmático. Inositol fosfatos, em especial o inositol 1,4,5trifosfato $\left(\mathrm{IP}_{3}\right)$ e seu derivado cíclico, liberam o íon cálcio do retículo sarcoplasmático (VAN BREEMEN; SAIDA, 1989).

$\mathrm{O}$ aumento intracelular dos segundos mensageiros cAMP e $\mathrm{IP}_{3}$ afeta indiretamente a contratilidade uterina, por meio de vias opostas, pela regulação da concentração intracelular de íon cálcio. Um aumento dos níveis citoplasmáticos de cAMP provoca relaxamento, enquanto que um aumento de $\mathrm{IP}_{3}$ causa contração (TABB; GARFIELD, 1992).

\section{Processo contrátil do músculo liso e a importância do íon cálcio}

Um conceito universal importante na contração de todos os músculos é a interação dos filamentos de actina e miosina para produzir tensão. Os filamentos de actina e miosina extraídos de músculos lisos interagem entre si da mesma forma como fazem a actina e a miosina no músculo esquelético. Ainda mais, o processo é ativado por íons cálcio e o ATP é degradado a ADP para fornecer energia à contração (GUYTON, 1988). A organização física da célula muscular lisa é mostrada na Figura 3, onde 
aparece um grande número de filamentos de actina, presos a corpos densos. Alguns desses corpos densos, por sua vez, ficam presos à membrana celular, enquanto outros ficam dispersos no sarcoplasma. Entremeados nos filamentos de actina, existem alguns poucos filamentos grossos, com diâmetro cerca de 2,5 vezes maior que o dos filamentos finos de actina. Presume-se que sejam os filamentos de miosina (GUYTON, 1988).

Todas as células musculares lisas contêm as proteínas contráteis actina, miosina e tropomiosina. A miosina é a proteína primária do filamento espesso do músculo liso e é composta de duas subunidades de alto peso molecular (ou cadeias pesadas) e dois tipos de subunidades de baixo peso molecular (ou cadeias leves). O peso molecular de cada subunidade de cadeia pesada é de cerca de 200.000 daltons, enquanto que o das subunidades de cadeia leve é de 20.000 e 17.000 daltons. A forma nativa hexamérica da miosina é configurada como uma região caudal helicoidal dupla, incluída no filamento grosso, com duas cabeças globulares que se protraem do filamento grosso a intervalos regulares para formar pontes de cruzamento. Essas regiões craniais contêm o domínio de ligação da actina, o local catalítico para a hidrólise de ATP e sua associação com as subunidades de cadeia leve. De acordo com a teoria do deslizamento das camadas de filamentos na contração muscular, filamentos grossos (miosina) e finos (actina) mover-se-ão uns sobre os outros (KAMM; STULL, 1985). 


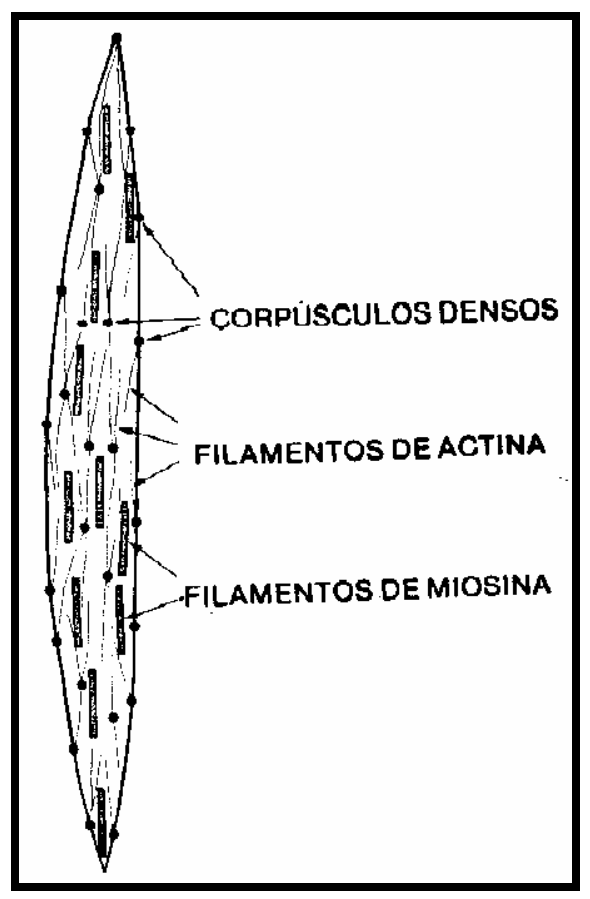

FIGURA 3. Disposição dos filamentos de actina e miosina na célula muscular lisa. (GUYTON, 1988)

O mecanismo dominante da ativação de íons cálcio, nos elementos contráteis nos músculos esqueléticos e cardíacos, são devidos a um sistema regulatório de íons cálcio nos filamentos finos, troponina-tropomiosina. A regulação das interações actina-miosina no músculo liso pelo íon cálcio é mais complexa, e diferentes mecanismos bioquímicos têm sido propostos, podendo ser divididos em duas classes gerais, envolvendo processos regulatórios de filamentos grossos e finos, respectivamente. Na regulação dos filamentos grossos, os íons cálcio ligam-se à calmodulina, e o complexo calmodulina-cálcio subseqüentemente liga-se à kinase da cadeia leve da miosina. A ativação desta proteína-kinase resulta na fosforilação da subunidade da miosina de cadeia leve (20.000 daltons), a cadeia leve-P, e na estimulação da atividade da $\mathrm{Mg}^{2+}$-ATPase da miosina do músculo liso. Também há evidências de que a atividade da miosina $\mathrm{Mg}^{2+}$-ATPase 
fosforilada do músculo liso pode ser aumentada pelos íons cálcio, possivelmente ligados diretamente à miosina (KAMM; STULL, 1985).

O segundo mecanismo de ativação do íon cálcio refere-se à regulação da interação actina-miosina no músculo liso, via componentes dos filamentos finos. Ebashi propôs qua a ativação dos íons cálcio é mediada pelo complexo de proteínas do filamento fino referida como leiotonina (EBASHI, 1983, apud KAMM; STULL, 1985). MARSTON, por outro lado, propôs dois mecanismos regulatórios ligados aos filamentos finos. Isolando-se filamentos finos, que são capazes de se ligar ao íon cálcio, a miosina $\mathrm{Mg}^{2+}$-ATPase ativa-se de modo dependente deste último. Este autor também concluiu que a fosforilação do compontente protéico de 21000 daltons nos filamentos finos é associada a um aumento na quantidade de locais de ligação de alta afinidade para o íon cálcio e a um decréscimo na concentração de íon cálcio requerido para a metade da ativação máxima da actina pela miosina $\mathrm{Mg}^{2+}$-ATPase (MARSTON, 1982, apud KAMM; STULL, 1985) (Figura 4).

Em resumo, certos agonistas que se ligam a receptores dos músculos lisos estimulam estas células a se contraírem, aumentando a concentração intracelular de cálcio. Isso eleva o cálcio ligado à calmodulina, resultando em um complexo cálcio-calmodulina, que se liga à kinase da cadeia leve da miosina, ativando a enzima. Essa ativação resulta na fosforilação da cadeia leve da miosina que subseqüentemente interage com a trifosfatase de adenosina magnesiana da actina ativada, produzindo contração (TABB; GARFIELD, 1992). 


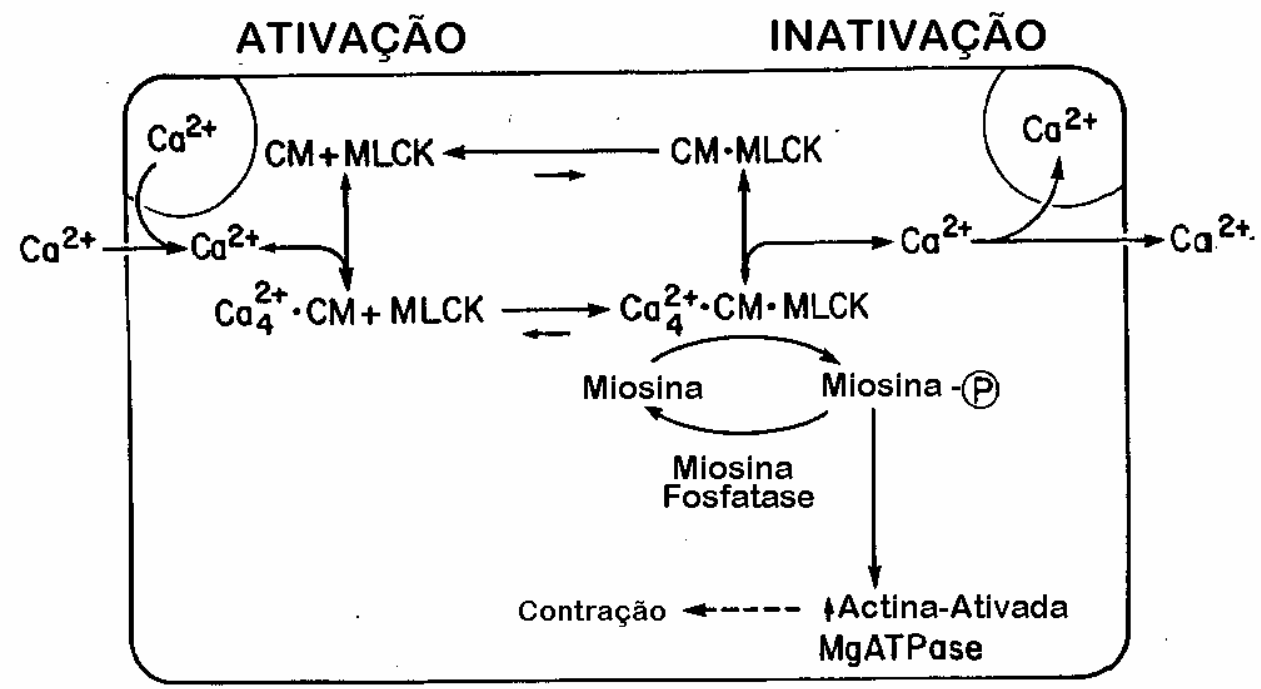

FIGURA 4. Esquema geral da regulação bioquímica da fosforilação da miosina nas células musculares lisas. $\mathrm{CM}=$ calmodulina; $\mathrm{MLCK}=$ kinase da cadeia leve da miosina; miosina-p= miosina fosforilada (KAMM; STULL, 1985).

O íon cálcio não é somente o mensageiro primário para a ativação da contração, mas é também importante em muitos outros eventos celulares, incluindo a atividade enzimática, regulação do ciclo celular e agindo como um segundo mensageiro através da interação com proteínas que se ligam ao íon cálcio (TABB; GARFIELD, 1992).

No miométrio, o fluido extracelular é a maior fonte de cálcio intracelular durante a contração, mas o retículo sarcoplasmático (RS) também serve como estoque intracelular. Durante a contração, a concentração intracelular de íons cálcio precisa aumentar para mais do que $1 \mu \mathrm{M}$. Isso é possível por meio da difusão passiva de íons cálcio através dos VGC ou por canais operados por receptores, abertos por potenciais de ação. Estoques intracelulares de íons cálcio também estão disponíveis para a contração, provavelmente como conseqüência da interação entre agonistas- 
receptores, resultando na produção de segundos mensageiros como a IP3, seguido pela liberação de cálcio pelo RS.

\section{A Participação das Prostaglandinas}

A gravidez representa um delicado equilíbrio entre a antigenicidade do feto (semi alogênico) e o sitema imune materno, que pode rejeitá-lo. Esse equilíbrio requer uma imunossupressão materna e uma ação antiinflamatória local; mas na hora do parto, uma resposta inflamatória seletiva pode gerar um mecanismo efetivo de parturição (KELLY, 1994).

Dentre os agentes imunossupressores, é proeminente a ação da progesterona, com seu efeito antiinflamatório. A ação da progesterona em manter a gestação é patente, pois quando usamos um antagonista como o RU486 (Mifepristone) podemos interromper a gestação em qualquer estágio e, se utilizado em conjunto com prostaglandinas, ele constitui um meio efetivo de induzir o aborto (KELLY, 1994).

As prostaglandinas, derivadas do metabolismo do ácido aracdônico, constituem um capítulo a parte, pois hoje seus derivados são utilizados para o amadurecimento do colo uterino e a indução do trabalho de parto (CARRARA, 1990). 
Numerosos estudos foram realizados para relacionar as prostaglandinas e o trabalho de parto, portanto vou citar apenas alguns. MANABE et al. (1985) verificaram que metabólitos da prostaglandina $F_{2 \alpha}$ aumentavam durante a indução do trabalho de parto por balão intracervical. Os mesmos autores constataram posteriormente (1992) que a viabilidade fetal não modificava os níveis plasmáticos e do líquido amniótico dessa prostaglandina (MANABE et al., 1992). MAZOR et al. (1990) realizaram um estudo em mulheres com trabalho de parto prematuro e infecção intramniótica, verificando que nelas o nível amniótico das prostaglandinas $\mathrm{E}_{2}$ e $\mathrm{F}_{2 \alpha}$ estava significativamente maior que no grupo sem infecção. NOORT et al (1989) demonstraram que o nível de metabólitos da prostaglandina $\mathrm{F}_{2 \alpha}$ aumentava durante $\mathrm{o}$ parto $\mathrm{e}$ declinava após a dequitação. E tanto a administração local de prostaglandinas $F_{2 \alpha}$ (CARRARA, 1990) e $E_{2}$ (FAIRLIE et al., 1990) amadurece o colo uterino quanto induz o trabalho de parto (KELLY, 1994).

Contudo, se a participação das prostaglandinas no amadurecimento do colo uterino e no desencadeamento do trabalho de parto está estabelecida, o mecanismo ainda está obscuro. Uma das hipóteses mais interessantes é a relação entre as citoquinas, os neutrófilos e as prostaglandinas. A prostaglandina $\mathrm{E}$ e a Intereucina 8 agiriam como intermediários, cuja ação seria controlada pelos níveis da progesterona. A prostaglandina E agiria como vasodilatador e a interleucina 8, como quimotáxico para neutrófilos, atraindo-os e degranulando-os. A ativação de neutrófilos geraria fatores de retroalimentação positiva, como a interleucina 
1 e o fator de necrose tumoral, agentes como a colagenase (que agiria no amadurecimento do colo uterino), além de uterotônicos como a prostaglandina E e o fator de ativação de plaquetas (KELLY, 1994).

A produção de prostaglandinas no útero grávido tem sido extensivamente estudada, mas no momento do parto é possível que os níveis de prostaglandinas sejam estimulados, para aumentar em locais discretos onde podem ser mais efetivos (líquido âmnico, decídua, miométrio, vasos sanguíneos) (KELLY, 1994).

De qualquer modo, seja por mudanças locais ou influência dos neutrófilos, as prostaglandinas $\mathrm{E}_{2}$ e $\mathrm{F}_{2 \alpha}$ são fundamentais para o mecanismo das contrações uterinas.

\section{A acupuntura, os íons $\mathrm{Ca}^{+2}$ e os agonistas e antagonistas da contração dos músculos lisos.}

A literatura concernente aos íons $\mathrm{Ca}^{+2}$, AMPc, GMPc e IP3 é pobre no que se refere a artigos publicados em inglês, sendo que a maioria dos artigos está em revistas chinesas, das quais temos acesso somente a alguns resumos, o que nos impede de avaliar a metodologia do trabalho, sendo uma limitação importante. 
Os primeiros relatos na língua inglesa datam de 1979, quando foram publicados os resumos do Simpósio Nacional de Acupuntura, Moxabustão e Anestesia por Acupuntura, realizado em Beijing. CHENG et al. (1979) compararam a concentração plasmática de AMPc antes e após a indução anestésica por acupuntura e a eficácia da anestesia. Nos casos onde a anestesia foi eficaz, os níveis plasmáticos de AMPc caíram significativamente, enquanto que nos outros casos eles permaneceram elevados. XU et al. (1979) também estudaram o nível de AMPc durante a analgesia por acupuntura, porém em coelhos e no núcleo caudado. O resultado foi que o limiar de dor aumentava à medida que os níveis de AMPc caíam. Na mesma publicação encontramos o único relato da literatura relacionando o efeito da acupuntura com as prostaglandinas. ZHOU; CHEN (1979) relacionaram os níveis plasmáticos de prostaglandina E e a eficácia da anestesia por acupuntura em várias cirurgias. Os melhores resultados analgésicos relacionavam-se com o aumento dos níveis plasmáticos da prostaglandina $\mathrm{E}$.

Outro estudo significativo foi realizado por LI et al. (1986). Estudando o efeito da acupuntura na função ventricular esquerda de pacientes portadores de infarto agudo do miocárdio, LI verificou que nos pacientes que foram submetidos à acupuntura os níveis de AMPc caíam (mas não a níveis significativos), assim como os de GMPc (esses sim a nível significativo). Nos casos controle os níveis de AMPc e GMPc não se modificaram. 
Os outros relatos da literatura estão em chinês e dispomos somente dos resumos. FANG (1994) mediu a concentração de AMPc e GMPc no plasma, no baço e no cérebro em ratos, após acupuntura em 2 pontos (em grupos de ratos diferentes, sendo que um recebeu acupuntura no ponto Zusanli e outro no ponto Taichong). Resultados: após acupuntura no ponto Zusanli os níveis plasmáticos de todos os nucleotídeos cíclicos no plasma aumentaram significativamente, a concentração de AMPc no baço tendeu a aumentar enquanto que os níveis corticais do AMPc tenderam a diminuir. As concentrações de AMPc, GMPc e a fração AMPc/GMPc foram diferentes no córtex cerebral e na medula espinhal entre os dois grupos de acupuntura.

Portanto, os dados sobre a relação entre AMPc e GMPc e acupuntura são controversos, não permitindo nenhuma conclusão.

Quanto ao íon $\mathrm{Ca}^{+2}$, os trabalhos chineses mais significativos são os que relacionam os efeitos da acupuntura antes e após a quelação do $\mathrm{Ca}^{+2}$. MIAO et al. (1993) e ZHANG et al. (1995) verificaram que os efeitos da acupuntura como tratamento de arritmia cardíaca em coelhos desapareciam após a quelação do $\mathrm{Ca}^{+2}$. Esses trabalhos mostram a importância do $\mathrm{Ca}^{+2}$ periférico para o efeito da acupuntura.

Quanto ao IP3, o único trabalho na literatura é de CHEN; HAN (1994). Esse experimento determinou as mudanças de IP3 no cérebro e na medula espinhal em ratos após acupuntura de alta frequiência $(100 \mathrm{~Hz})$, demonstrando que os níveis de IP3 no cérebro aumentam após a 
eletroacupuntura, enquanto que os níveis medulares diminuem, voltando ao normal cerca de 30 minutos após o término da estimulação.

Embora os dados não possam ser conclusivos, os trabalhos sugerem que ocorrem mudanças no cAMP, cGMP, $\mathrm{Ca}^{+2}, \mathrm{IP} 3$ e nas prostaglandinas durante a estimulação dos pontos de acupuntura. 
PROPOSIÇÃO 
Como a análise da literatura não esclarece qual o mecanismo de ação da acupuntura no aumento da atividade uterina, nem estabelece um modelo animal para esse estudo, propusemo-nos a investigar:

1. um modelo animal que reproduzisse o aumento da atividade uterina após a eletroacupuntura;

2. o comportamento do útero após lesões no $\mathrm{SNC}$;

3. a influência dos CEBF no mecanismo de ação da acupuntura nas modificações da AEU. 
MATERIAIS E MÉTODOS 
O projeto foi aprovado pela comissão de ética do departamento de Obstetrícia e Ginecologia do Hospital das Clínicas da USP e pela Comissão de Ética e Análises de Pesquisas do Hospital das Clínicas da Faculdade de Medicina da USP.

O projeto experimental foi mudando a cada momento em que os resultados assim permitiam. Para facilitar a compreensão do que ocorreu, a pesquisa será dividida em quatro fases. Pode-se dividir os experimentos em crônicos (primeira, segunda e terceira fases, onde o eletrodo era implantado antes da eletroacupuntura) e agudos (onde o animal era submetido ao registro uterino e sacrificado a seguir). As fases dos experimentos foram:

1. Inicialmente procuramos implantar eletrodos no SNC e útero em ratas não prenhes e colocá-las com o macho para o acasalamento. A eletroacupuntura nessa fase era realizada com o animal desperto, mas optamos por realizá-la sempre com o animal anestesiado, pois de outro modo os resultados poderiam advir do estresse do animal. Nenhum dos animais engravidou, a despeito do aparecimento de espermatozóides no esfregaço vaginal. Acreditamos que o eletrodo uterino tenha funcionado como um dispositivo intra-uterino (DIU), impedindo a prenhez. Perdemos muitos animais que, após o registro de repouso, perdiam o soquete por infecção ou durante o acasalamento, por esse motivo não conseguindo registros após a eletroacupuntura. Estão contidos neste estudo seis 
animais não prenhes, para estudo da atividade uterina de repouso e das relações entre a AEU e do SNC.

2. Na segunda fase colocamos o eletrodo em SNC e útero após a constatação da prenhez. Apesar do sucesso da cirurgia, os dados obtidos durante essa fase foram pobres, e optamos por não mais colocar eletrodos no SNC, pois o método era trabalhoso e a atividade uterina poderia ser provocada pelos eletrodos no SNC. Desta fase temos 2 ratas prenhes com registro antes e após a eletroacupuntura.

3. Na terceira fase colocamos somente o eletrodo uterino em ratas prenhes e não prenhes e tentamos inibir o aumento da atividade elétrica após a acupuntura por meio de lesões no SNC. Apesar de verificarmos o aumento da AEU após a eletroacupuntura em todos os experimentos, não conseguimos efeito nenhum com as lesões do SNC. Desta fase temos seis ratas prenhes e duas não prenhes, com registro antes e após a eletroacupuntura.

4. A quarta fase foi constituída de quatro experimentos para verificar a ação do sistema nervoso central e periférico (experimentos agudos), onde os eletrodos foram inseridos no útero e o registro foi feito logo após lesões na medula vertebral, após denervação do útero com álcool e experimentos in vitro. Desta fase temos onze ratas, sete não prenhes e quatro prenhes. 
TABELA 1. DIVISÃO DOS ANIMAIS POR EXPERIMENTO

\begin{tabular}{|c|c|c|c|}
\hline Experimento & $\begin{array}{c}\text { Total de } \\
\text { animais } \\
\text { prenhes }\end{array}$ & $\begin{array}{c}\text { Total de } \\
\text { animais não } \\
\text { prenhes }\end{array}$ & Eletroacupuntura \\
\hline $\begin{array}{c}\text { Ratas não prenhes, com } \\
\text { eletrodos no SNC e útero. }\end{array}$ & 0 & 6 & Não \\
\hline $\begin{array}{c}\text { Ratas prenhes, com eletrodos no } \\
\text { SNC e útero }\end{array}$ & 2 & 0 & Sim \\
\hline $\begin{array}{c}\text { Eletrodos uterinos implantados } \\
\text { em ratas prenhes e não prenhes, } \\
\text { tentativa de lesão em SNC }\end{array}$ & 6 & 2 & Sim \\
\hline $\begin{array}{c}\text { Experimentos agudos, lesões } \\
\text { medulares na altura de T1. }\end{array}$ & 1 & 1 & Sim \\
\hline $\begin{array}{c}\text { Experimentos agudos, } \\
\text { denervação uterina com álcool } \\
\text { absoluto. }\end{array}$ & 1 & 2 & Sim \\
\hline $\begin{array}{c}\text { Experimentos agudos, } \\
\text { denervação uterina com álcool } \\
\text { absoluto e isolamento da artéria } \\
\text { do rabo. }\end{array}$ & 0 & 2 & Sim \\
\hline $\begin{array}{c}\text { Experimentos in vitro } \\
\text { (Eletroestimulação) }\end{array}$ \\
\hline
\end{tabular}

\section{SELEÇÃO DE ANIMAIS}

$\Rightarrow$ Foram selecionadas 27 ratas Wistar, conforme tabela 1, com peso variando entre 200 e 300 gramas (de dois a três meses de idade). Todas as ratas foram fornecidas pelo biotério da Faculdade de Medicina da USP, de onde eram trazidas no mínimo sete dias antes de qualquer experimento para facilitar a aclimatação, sendo acondicionadas em gaiolas de plástico, em número de duas a quatro por gaiola. Após os experimentos, os animais não prenhes eram acondicionados em gaiolas de metal ou plástico e os prenhes em gaiolas plásticas, em número de um por gaiola. A razão pela qual a rata prenhe tem que ficar em gaiola plástica é que, 
após o parto, os fetos ficam presos nos orifícios da gaiola de metal, degolando-os. Os animais foram divididos conforme a tabela 1.

\section{METODOLOGIA DOS EXPERIMENTOS CRÔNICOS}

$\Rightarrow$ Prenhez: três a quatro ratas foram colocadas com um macho para procriação, por dois dias. Foram consideradas prenhes as fêmeas que apresentaram fetos no útero no momento da colocação do eletrodo uterino. A implantação dos soquetes foi realizada de oito a dez dias após o contato com o macho.

$\Rightarrow$ Preparação do soquete uterino: O soquete uterino foi feito de "chip" de computador, serrado e lixado até que permanecessem dois terminais, além de quatro orifícios para fixação, e os eletrodos foram manufaturados da seguinte maneira:

$\Rightarrow$ Os eletrodos consistiram de fio marca Stablohm 650, tamanho 0,06 e de resistência de 18 Ohm/pé (Califórnia Fine Wire Company, Grover Beach, CA, EUA), soldados diretamente na parte inferior do soquete, onde estão os terminais. Após a soldagem dos eletrodos, estes foram recobertos com cera para osso, de modo a isolar o soquete do meio ambiente.

$\Rightarrow$ Implantação do soquete uterino: a implantação do soquete foi feita após a anestesia do animal com Cloridrato de cetamina a $158 \mathrm{mg} / \mathrm{Kg}$, intraperitoneal. Após a tricotomia do animal, foi realizada a cirurgia para implantação do eletrodo uterino. Foram feitas duas incisões na pele, a 
maior $(4-6 \mathrm{~cm})$ na região abdominal e a menor (cerca de $1,5 \mathrm{~cm}$ ) na região cervical, na linha média logo abaixo do occipício. Com a utilização de uma agulha para anestesia raquídea, passaram-se os fios desde a região cervical através do subcutâneo até o abdome, os quais foram fixados em um dos cornos uterinos, dando-se um ponto no miométrio e deixando uma pequena parte previamente descascada (cerca de $2 \mathrm{~mm}$ ) no interior deste, repetindo-se a operação a $5 \mathrm{~mm}$ do primeiro eletrodo. Os fios foram fixados com fio de nailon 6-0 (Ethicon). O abdome foi suturado, deixando-se o fio saindo de uma pequena abertura através do peritôneo.e realizou-se a fixação do soquete com pontos de algodão recobertos com resina acrílica.

$\Rightarrow$ Preparação do soquete SNC e uterino: oito animais (seis prenhes e dois não) foram submetidos à neurocirurgia para implantação do soquete. $\mathrm{O}$ soquete colocado na cabeça do animal obedeceu ao esquema da Figura 5.

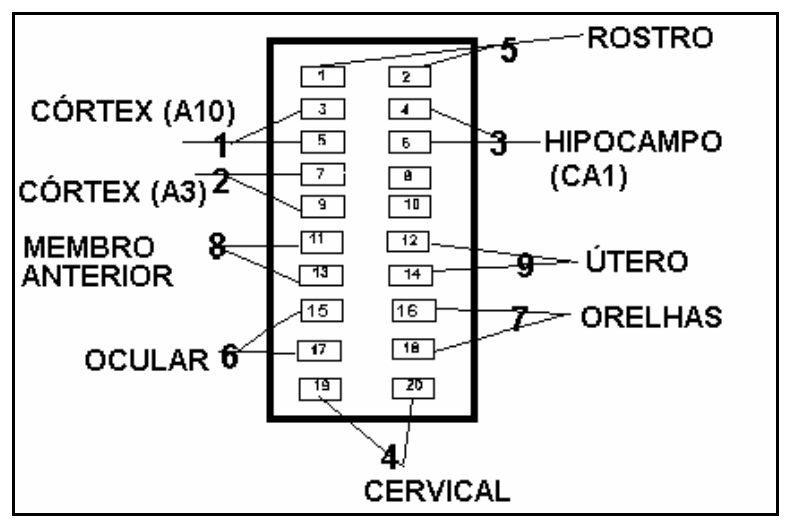

FIGURA 5: Localização dos eletrodos no soquete (vista superior) 
O soquete foi feito de "chip" de computador, serrado e lixado até adquirir a forma acima, e os eletrodos foram manufaturados da seguinte maneira:

- Rostro, útero, orelhas, cervical, ocular e membros: os eletrodos consistiram de fio Stablohm 650, tamanho 0,06 e de resistência de 18 Ohm/pé (Califórnia Fine Wire Company, Grover Beach, CA, EUA), soldados diretamente na parte inferior do soquete, onde estão os terminais.

- Áreas corticais 3 e 10; dois fios foram passados através de um tubo plástico de aproximadamente $2 \mathrm{~mm}$ de espessura e $3 \mathrm{~mm}$ de altura, dobrados e fixados com cola Super Bonder (3M, São Paulo). As bordas inferiores foram dobradas e descascadas próximo ao tubo, e as extremidades proximais ao soquete foram fixadas com solda nos terminais correspondentes.

- Área hipocampal $\mathrm{CA}_{1}$ : o eletrodo foi feito de dois fios Stablohm 650, tamanho 0,06, de resistência de 18 Ohm/pé (Califórnia Fine Wire Company, Grover Beach, CA, EUA), descascados na ponta e colados um no outro com cola Super Bonder (3M, São Paulo), de modo que as pontas descascadas ficassem a cerca de $1 \mathrm{~mm}$ de distância uma da outra.

$\Rightarrow$ Implantação do soquete: A implantação do soquete foi feita após a anestesia do animal com Cloridrato de cetamina a $158 \mathrm{mg} / \mathrm{Kg}$, intraperitoneal. Foi feita a tricotomia, ajuste no aparelho estereotácico e 
abertura da pele até a exposição das suturas cranianas, em especial o bregma. Após a localização deste, os pontos referentes às áreas corticais e subcorticais foram marcados com caneta. A localização dessas áreas foi feita conforme atlas (PAXINOS; WATSON, 1982). A área cortical 10 localiza-se 3,0 mm anterior e 2,0 mm lateral ao bregma. A área 3 a 1,5 $\mathrm{mm}$ posterior e 3,0 $\mathrm{mm}$ lateral ao bregma. A região hipocampal $\mathrm{CA}_{1}$ localiza-se a 4,5 $\mathrm{mm}$ posterior e $2,5 \mathrm{~mm}$ lateral ao bregma, e a 2,8 $\mathrm{mm}$ de profundidade (2,2 $\mathrm{mm}$ da dura-máter). Após a perfuração dos pontos acima com furadeira elétrica, foram acrescentados 2 furos e colocados 2 parafusos no osso para ajudar na fixação. O eletrodo subcortical foi soldado no soquete após a colocação com ajuda do aparelho estereotácico e fixado com acrílico. Após a soldagem do eletrodo subcortical, baixou-se o soquete, colocaram-se os eletrodos corticais e isolou-se a região inferior do soquete com cera de osso.

$\Rightarrow$ Eletrodos Musculares: os eletrodos musculares foram fixados em um membro anterior, unilateral, dando-se um ponto com o fio e deixando uma área descascada no interior do músculo, no bíceps. Os eletrodos de rostro foram colocados um de cada lado, o mesmo acontecendo em olhos, musculatura retroauricular e região cervical.

$\Rightarrow$ Registro de atividade uterina elou cerebral: após constatada a prenhez, os registros foram feitos entre o $17^{\circ}$ e o $19^{\circ}$ dia de prenhez (a duração da prenhez em ratas é de cerca de 21 dias). Nas ratas não prenhes, o registro foi feito de duas a quatro semanas após a implantação dos eletrodos. Todos os experimentos foram feitos sob anestesia profunda com 
Equidezin (Hidrato de Cloral, Sulfato de Magnésio, Tionembutal, Propilenoglicol e Água destilada, 0,3 ml/100g, intraperitoneal) ou Cloridrato de cetamina a $158 \mathrm{mg} / \mathrm{Kg}$, intraperitoneal. A mudança de anestésico foi devida à presença de Sulfato de Magnésio no primeiro, fato que poderia levar a relaxamento muscular. Os animais foram registrados por 30 minutos antes da eletroacupuntura, para controle da atividade uterina. Após esse período foram submetidos a 90 minutos de eletroacupuntura, utilizando-se agulhas de aço inoxidável e cabo de cobre, de medidas 0,32 X 1,3 mm, da marca Hwato (Suzhou, República Popular da China), conectadas ao aparelho de eletroacupuntura WQ-6F (Beijing, República Popular da China), com a frequiência de $15 \mathrm{~Hz}$, contínua, de intensidade suficiente para provocar contrações musculares. Os pontos de acupuntura utilizados foram o Sanyinjiao (BP6), localizado na face interna, inferior e posterior da tíbia, e o ponto Zusanli (E36), localizado próximo à junção superior entre a tíbia e a fíbula. A escolha do ponto Sanyinjiao decorreu do fato de que todos os experimentos em humanos utilizavam-se desse ponto para a indução do trabalho de parto. Como precisávamos de outro ponto (para o estímulo elétrico necessitamos de dois pólos de estimulação), escolhemos o Zusanli, pois a grande maioria dos trabalhos experimentais com ratos utilizam-se desse ponto. O tempo de 90 minutos foi estabelecido em experimentos anteriores, onde foi verificado que após 30 e 60 minutos não se observava um aumento marcante da atividade uterina, fato que ficava patente à partir de 90 minutos de eletroestimulação. 
$\Rightarrow$ Registros: os registros em papel foram feitos por meio do aparelho Neurofax série EEG-4400 (Nihon Kohden, Tóquio, Japão), e com eles foi avaliada a atividade uterina e a do SNC.

\section{METODOLOGIA DOS EXPERIMENTOS AGUDOS:}

$\Rightarrow$ Em duas ratas (uma prenhe e outra não) foi realizada uma lesão medular com tesoura na altura de T1, de modo a preservar as funções vitais, e registrada a atividade uterina de modo idêntico ao dos experimentos crônicos.

$\Rightarrow$ Em três ratas (uma prenhe e duas não) o útero foi denervado utilizando-se álcool absoluto em algodão e tendo-se o cuidado de passá-lo em todo o perímetro externo e interno do útero. A eletroacupuntura foi realizada nos pontos de acupuntura de duas ratas e no pescoço da terceira (não prenhe), imediatamente sobre a carótida, longe de qualquer ponto de acupuntura.

$\Rightarrow$ Em dois animais o útero foi denervado e a cauda da rata foi dissecada, isolando-se a artéria e seccionando-se as outras estruturas. A eletroacupuntura foi aplicada no rabo, distal à artéria, e foi feito registro dos sinais elétricos que chegavam ao útero antes e após o clampeamento da artéria.

$\Rightarrow$ Foram realizados quatro experimentos in vitro (dois com ratas prenhes e dois não). $\mathrm{O}$ útero foi retirado e foram colocados os eletrodos em um dos 
cornos. Após a fixação dos eletrodos, o útero foi colocado em um béquer contendo solução salina a $0,9 \%$ a $37^{\circ} \mathrm{C}$. Os registros foram feitos antes e após 30 minutos de eletroestimulação na solução salina (Figura 6).

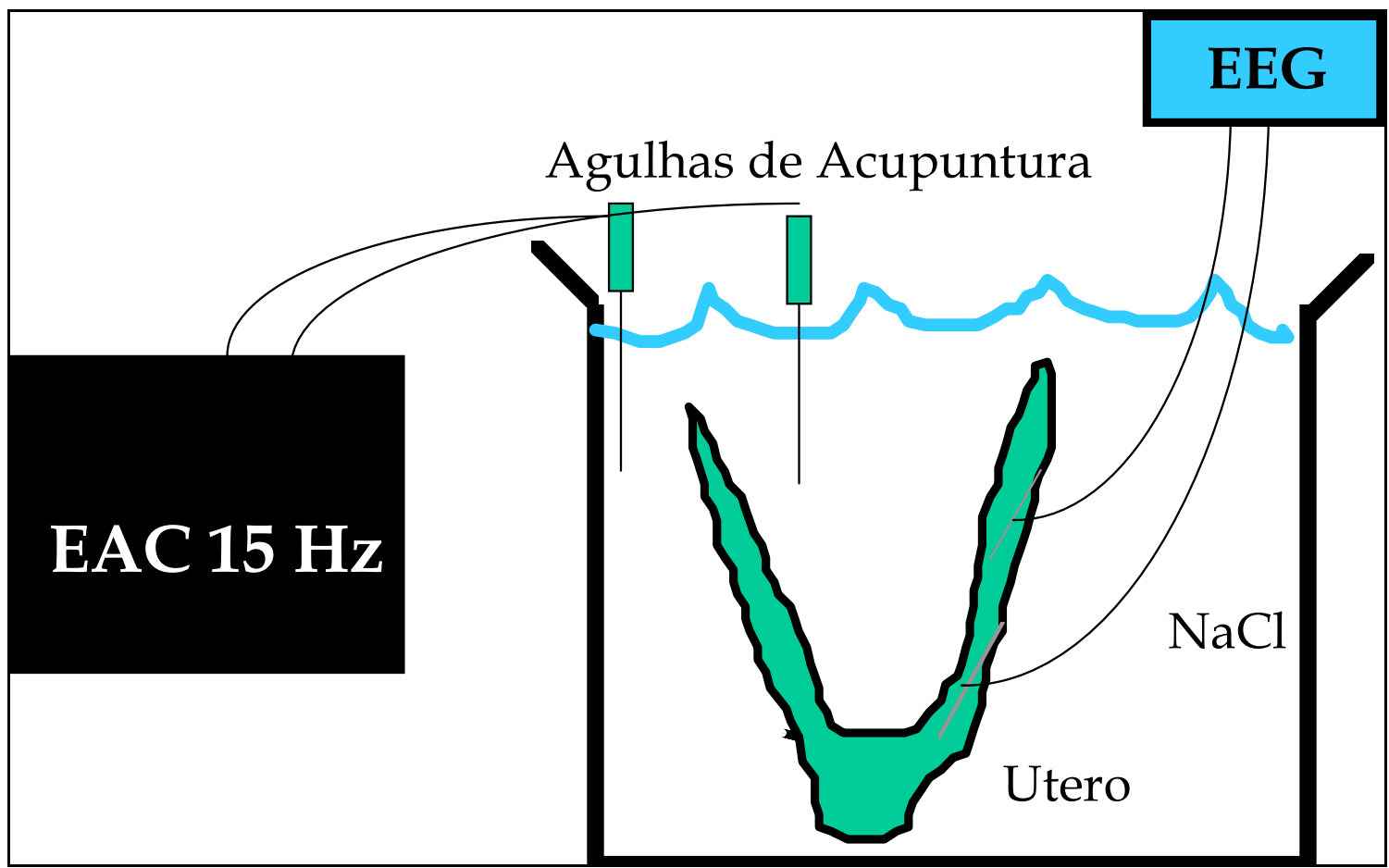

FIGURA 6. Esquema do experimento in-vitro. A eletroestimulação foi aplicada na solução fisiológica, como em um CEBF. 


\section{RESULTADOS}


1. Atividade espontânea: a atividade elétrica de repouso foi semelhante nas ratas prenhes $(1,87+/-2,35$ eventos/3 $\min , \mathrm{n}=8)$ e não prenhes $(2,31+/$ $1,57$ eventos/3 min, $\mathrm{n}=8)(\mathrm{p}>0.1)($ Tabela 2$)$.

TABELA 2. ATIVIDADE ELÉTRICA UTERINA DE REPOUSO (AEUR), EM EVENTOS/3 MINUTOS. COMPARAÇÃO ENTRE RATAS PRENHES E NÃO PRENHES (* MÉDIA DE QUATRO EXPERIMENTOS, (** - MÉDIA DE TRÊS EXPERIMENTOS) (*** TESTE T DE STUDENT, NÃO PAREADO)

\begin{tabular}{|c|c|c|c|}
\hline Ratas não prenhes & AEUR & Ratas prenhes & AEUR \\
\hline 1 & 3 & 1 & 2 \\
\hline 2 & 5 & 2 & 2 \\
\hline $3^{*}$ & 0,5 & 3 & 0 \\
\hline 4 & 3 & 4 & 0 \\
\hline 5 & 0 & 5 & 7 \\
\hline $6^{* *}$ & 2 & 6 & 3 \\
\hline 7 & 2 & 7 & 0 \\
\hline 8 & 3 & 8 & 1 \\
\hline Média & 2,31 & & 1,87 \\
\hline Desvio padrão & 1,57 & & 2,35 \\
\hline $\mathrm{p}^{* * *}$ & & & 0,3 \\
\hline
\end{tabular}

2. Atividade pós-eletroacupuntura nas ratas prenhes: a AEU aumentou de $1,87+/-2,35$ eventos $/ 3 \min (\mathrm{n}=8)$ para $28,06+/-17,27$ eventos/3 $\mathrm{min}$ após 90 minutos de eletroacupuntura $(\mathrm{p}<0.01)$. Os resultados podem ser observados na tabela 3 . Na Figura 7 são apresentados dois exemplos do aumento da AEU. 
TABELA 3. ATIVIDADE ELÉTRICA EM RATAS PRENHES ANTES E APÓS A ELETROACUPUNTURA (EVENTOS EM 3 MINUTOS). NESTA FASE NÃO TEMOS REGISTROS DE RATAS NÃO PRENHES PÓS-ELETROACUPUNTURA, POIS AS RATAS NÃO PRENHES DA FASE 1 PERDIAM O SOQUETE APÓS TENTATIVA DE ACASALAMENTO, RESTANDO O REGISTRO DE REPOUSO (* - MÉDIA DE DOIS EXPERIMENTOS) (** - TESTE T DE STUDENT, PAREADO)

\begin{tabular}{|c|c|c|}
\hline Rata prenhe & $\begin{array}{c}\text { Atividade elétrica uterina de } \\
\text { repouso }\end{array}$ & $\begin{array}{c}\text { Atividade elétrica uterina pós- } \\
\text { elétroacupuntura }\end{array}$ \\
\hline 1 & 2 & 45 \\
\hline $2^{*}$ & 2 & 16,5 \\
\hline 3 & 0 & 54 \\
\hline 4 & 0 & 8 \\
\hline 5 & 7 & 23 \\
\hline 6 & 3 & 38 \\
\hline 7 & 0 & 7 \\
\hline 8 & 1 & 33 \\
\hline Média & 1,87 & 28,06 \\
\hline $\begin{array}{c}\text { Desvio } \\
\text { padrão }\end{array}$ & 2,35 & 17,27 \\
\hline p $^{* *}$ & & 0,001 \\
\hline
\end{tabular}




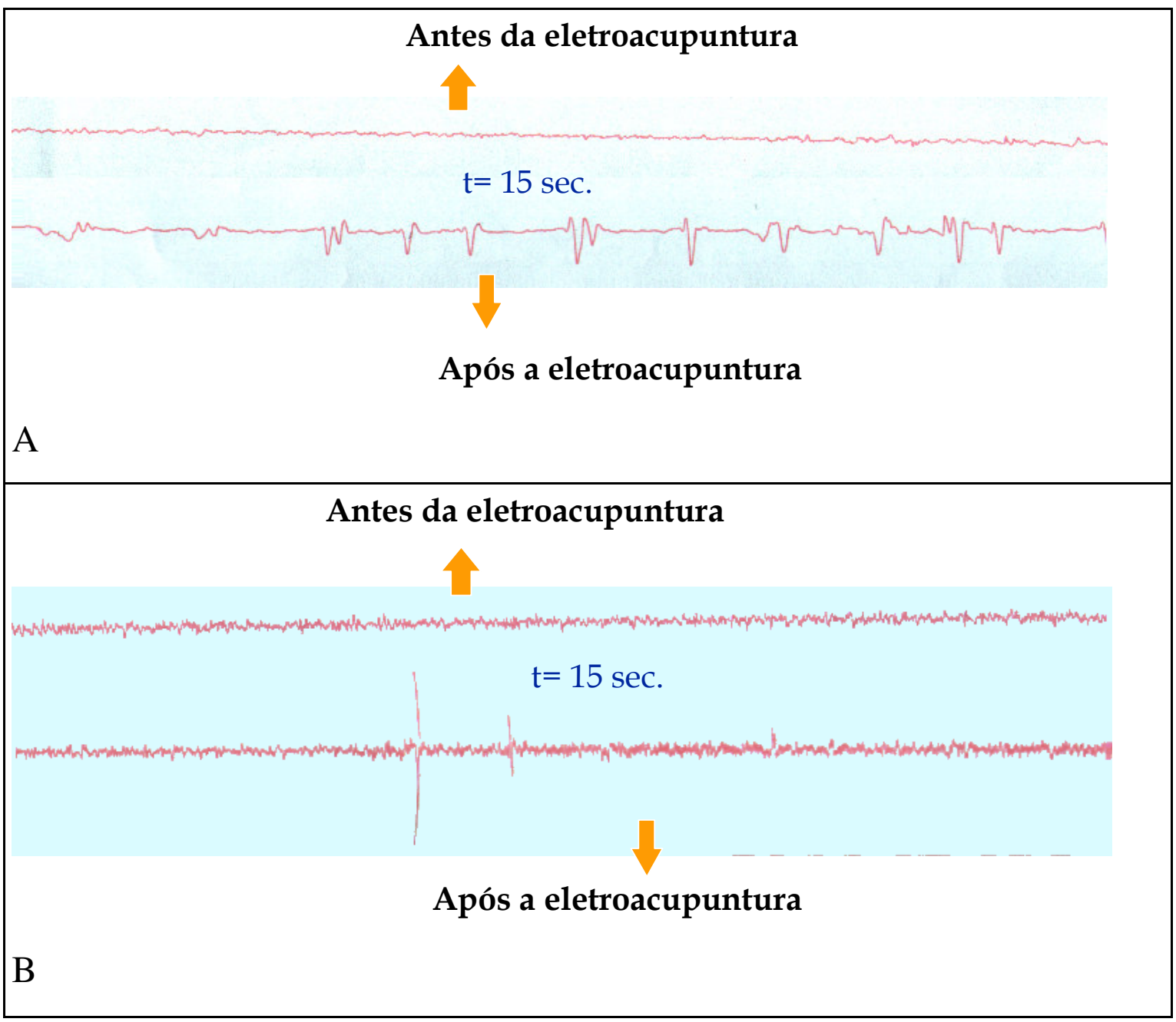

FIGURA 7. Aumento da atividade elétrica após 90 minutos de eletroacupuntura. Embora os padrões das figuras A e B sejam diferentes, o aumento da atividade elétrica é patente nos dois casos.

3. Avaliação da atividade do SNC e uterina. Em 3 das 8 ratas avaliadas, observamos um sincronismo entre o aumento da atividade cerebral e uterina. O fenômeno ocorre antes (Figura 8) e após a eletroacupuntura (Figura 9). 


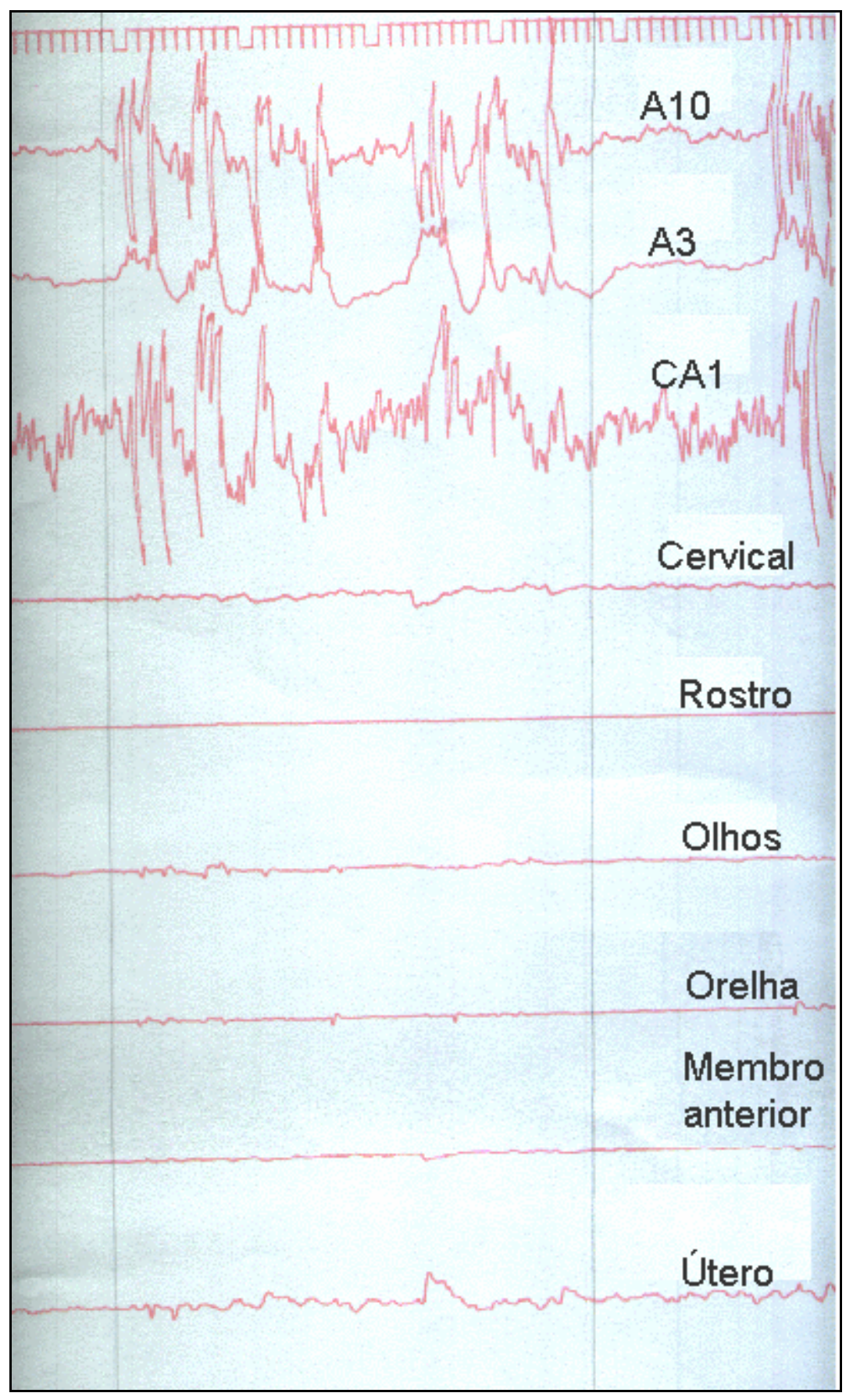

FIGURA 8. Sincronismo entre o aumento da atividade elétrica cerebral e a AEU. Esse registro foi feito antes do estímulo da eletroacupuntura. (A10: Área cortical 10, A3: Área cortical 3, CA1: Área hipocampal CA1) 


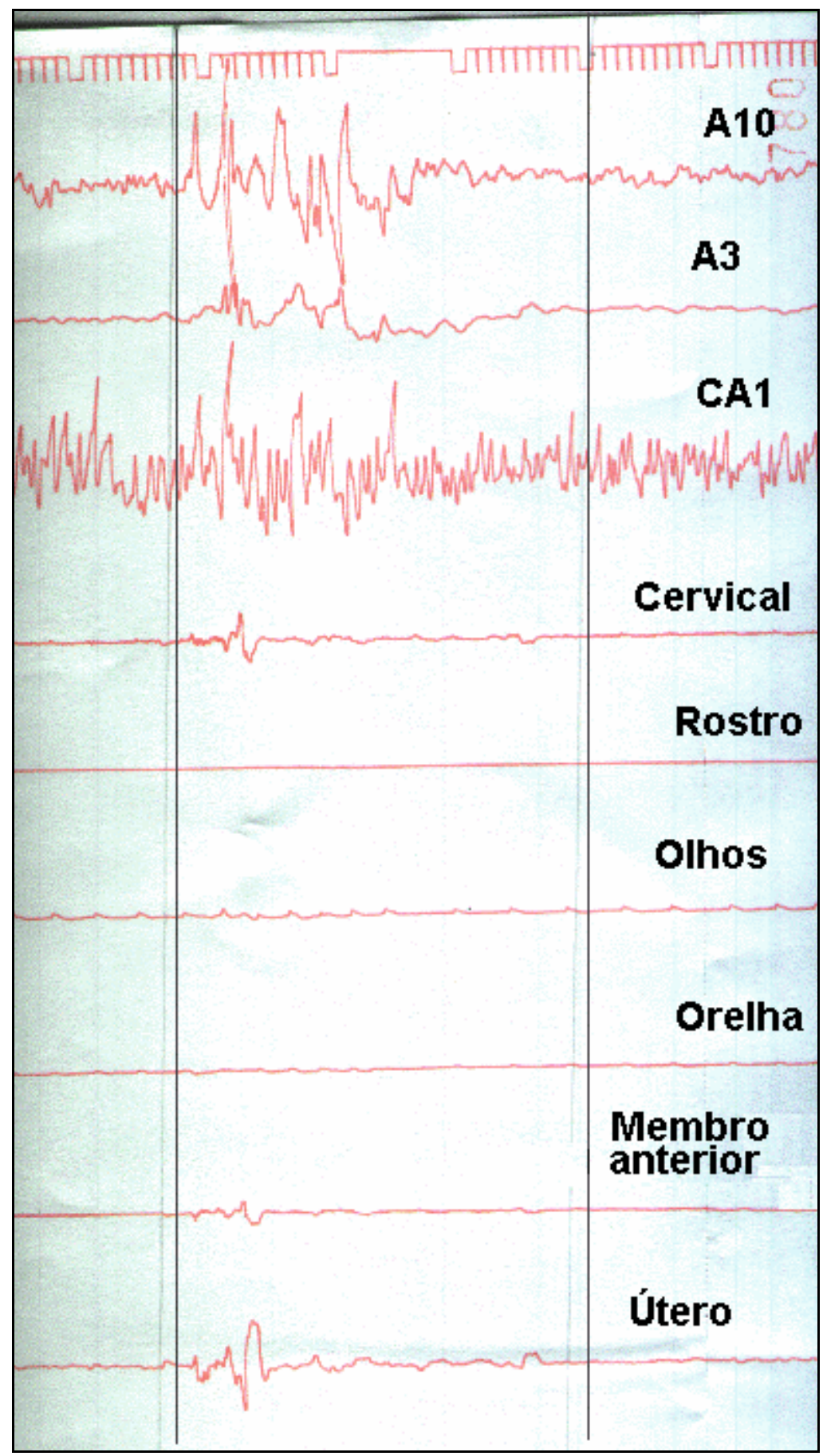

FIGURA 9. Sincronismo entre o aumento da atividade elétrica cerebral e uterina após 90 minutos de eletroacupuntura (A10: Área cortical 10, A3: Área cortical 3, CA1: Área hipocampal CA1)

4. A AEU continuou aumentando após a eletroacupuntura mesmo após as lesões medulares e a denervação do útero com álcool absoluto ( 9 dos 11 
experimentos agudos estão resumidos na tabela 4, os demais estão descritos no item 5).

Tabela 4. Experimentos Agudos, atividade elétrica Uterina (AEU) aNTES E APós a ELETROESTIMULAÇÃO (EVENTOS / 3 MINUTOS)

\begin{tabular}{|c|c|c|c|}
\hline Número do experimento & Tipo de experimento & AEU antes & AEU após \\
\hline 1 & Lesão medular (T1) prenhe & 0 & 6 \\
\hline 2 & Lesão medular (T1) não prenhe & 1 & 13 \\
\hline 3 & Denervação do útero com álcool, prenhe & 0 & 7 \\
\hline 4 & Denervação do útero com álcool, não prenhe & 0 & 7 \\
\hline 5 & in vitro 1, prenhe & 0 & 8 \\
\hline 6 & in vitro 2, não prenhe & 0 & 6 \\
\hline 7 & in vitro 3, prenhe & 1 & 8 \\
\hline 8 & in vitro 4, não prenhe & 0 & 17 \\
\hline 9 & $\begin{array}{c}\text { Denervação do útero com álcool, não prenhe, } \\
\text { eletroestimulação na região da carótida }\end{array}$ & 0 & 14 \\
\hline
\end{tabular}

5. Ao cortarmos todas as estruturas do rabo de duas ratas, com exceção da artéria, os sinais elétricos continuaram chegando no útero. Ao clampearmos a artéria, os sinais elétricos desapareceram do útero (Figura 10)

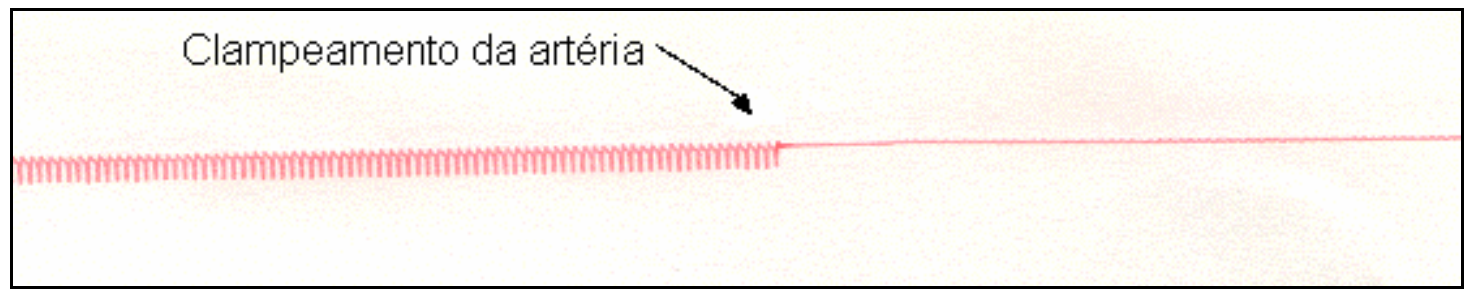

FIGURA 10. Eletroacupuntura aplicada no rabo do animal, com todas as estruturas seccionadas com exceção da artéria do rabo. Note que os sinais elétricos de $15 \mathrm{~Hz}$ desaparecem completamente após o clampeamento da artéria. 
6. A AEU aumentou após a retirada do útero e quando colocamos em solução fisiológica a $37^{\circ}$ e, ainda, após 15 minutos de estímulo elétrico na solução salina.

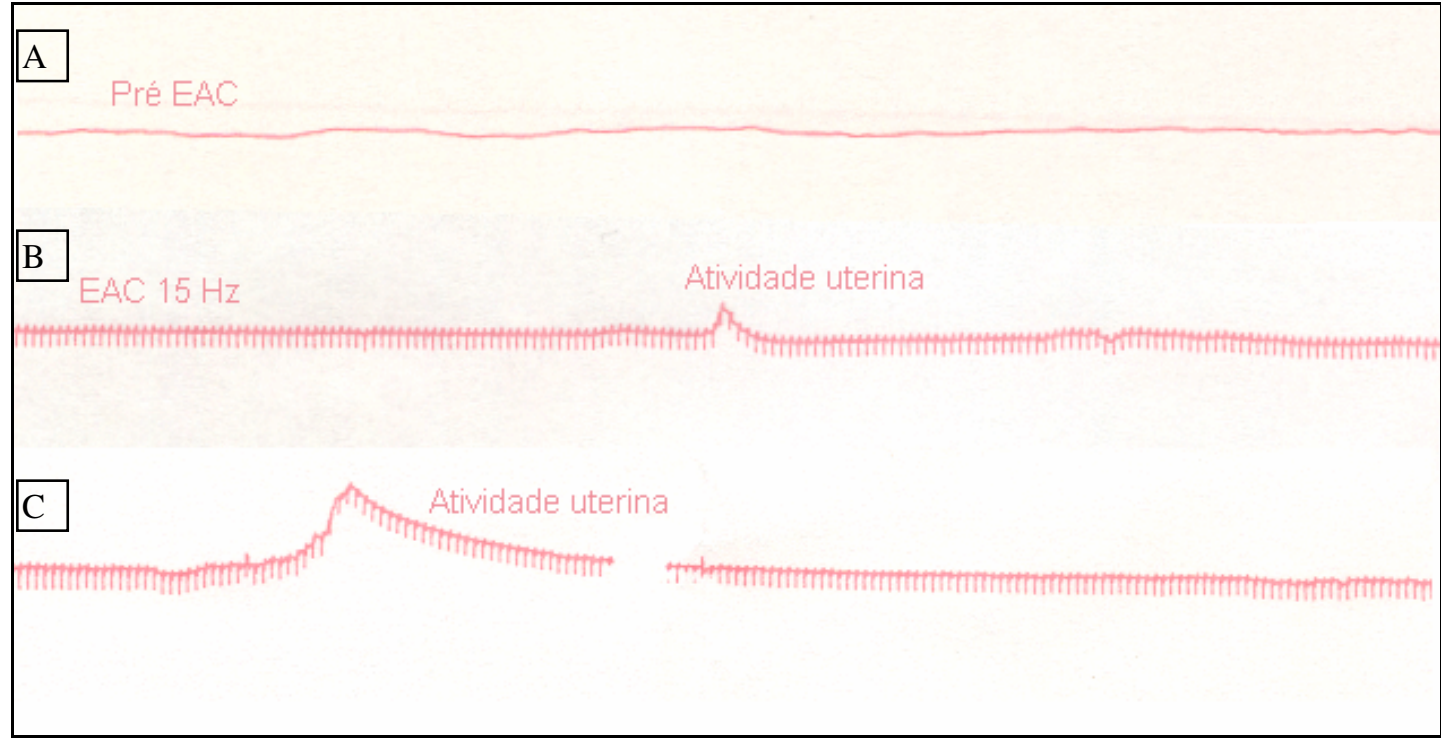

FIGURA 11. Eletroacupuntura na região da carótida, fora de ponto de acupuntura, diretamente sobre a artéria, em rata com denervação uterina com álcool absoluto. $O$ registro controle não mostra alterações de despolarização (A), enquanto que após a eletroestimulação verificamos os sinais de $15 \mathrm{~Hz}$ registrado, nos eletrodos uterinos e alterações da atividade uterina $(B)$, fato que se repetiu $(C)$. Note a inversão de potencial em $B$, fato notado em alguns registros. 
DISCUSSÃO 
Discutir os resultados desses experimentos implica a discussão dos dogmas relacionados com a introdução da acupuntura e da medicina tradicional chinesa (MTC) na prática médica no Brasil. A maior dificuldade para o iniciante na MTC é o uso das metáforas e a tradução literal dos termos em chinês. Como a MTC utiliza descrições comparativas e como segundo ela a fisiologia baseia-se no funcional e não no anatômico, o médico ocidental tende a achar a MTC de difícil compreensão, sem sentido e, o que é ainda pior, que o ensinamento contém um significado oculto, misterioso, estimulando o pensamento mágico e o misticismo. Toda essa atitude (mística) foi muito propagada na mídia nos últimos anos, colocando a acupuntura e a MTC junto com outras técnicas sem comprovação científica, gerando um preconceito imenso na classe médica (FARBER, 1997).

Tal situação começou a modificar-se a partir de meados da década de 70, com a descoberta de substâncias endógenas semelhantes à morfina (endorfinas) (HUGUES et al., 1975). A partir de então, vários pesquisadores relacionaram os efeitos analgésicos da acupuntura às endorfinas (SJÖLUND et al., 1977; POMERANZ; WARMA, 1979; SODIPO et al., 1981), levando a uma espécie de "corrida" entre os pesquisadores para descobrir como o SNC participava na ação analgésica da acupuntura. A partir daí descobriu-se que o ponto de acupuntura era uma região rica em terminações nervosas; que havia uma via de acesso ao mesencéfalo através da medula espinhal e formação reticular; que a região dorsal do estrato cinzento periaquedutal era a porta de entrada do estímulo da acupuntura no SNC; que havia uma via 
aferente e outra eferente, e, ainda, outra liberadora de beta-endorfinas que agiria nas sinapses do núcleo arqueado hipotalâmico; em suma, que a ação do estímulo nos pontos de acupuntura estava relacionada ao SNC (FARBER; TIMO-IARIA, 1994).

Esse movimento científico possibilitou algumas conclusões:

1. a acupuntura possui efeitos analgésicos específicos;

2. toda a ação da acupuntura faz-se através do SNC;

e ainda levou a alguns "dogmas" como:

1. a acupuntura é uma técnica exclusivamente analgésica;

2. os estudos no SNC explicariam todo o funcionamento da acupuntura.

Essas conclusões levaram à aceitação gradual da acupuntura no meio médico ocidental, mas devido ao caráter analgésico das pesquisas o uso ficou restrito a grupos de estudo e tratamento de dor, como anestesistas, fisiatras, ortopedistas e neurologistas.

Curiosamente, em nosso meio, o primeiro trabalho apresentado em congresso de medicina ocidental foi relativo à indução do trabalho de parto com estímulos elétricos sobre pontos de acupuntura (FARBER et al., 1989). Apesar disso, a maioria dos serviços universitários relacionados com a acupuntura estão em grupos de estudo da dor. 
Todo esse retrospecto (fartamente documentado na revisão de literatura) levou-nos erroneamente a procurar as respostas às nossas questões no SNC.

Felizmente nosso primeiro problema foi resolvido a contento, pois conseguimos um modelo experimental utilizando ratas Wistar, animal facilmente encontrável no nosso biotério. A primeira surpresa foi verificar que a $\mathrm{AEU}$ de repouso era semelhante em ratas prenhes e não prenhes, fato consistente com a literatura, pois a AEU de vários animais (gatos, coelhos e ratos) só aumenta no dia do parto, em geral com a formação de conjunto de despolarizações, com uma média de 20 despolarizações por conjunto, correspondendo cada conjunto a uma contração uterina (WOLFS; LEEUWEN, 1979).

Uma vez obtido o modelo experimental, tentamos estudar o comportamento do SNC e da AEU. Quando encontramos sincronicidade entre a AEU e a atividade elétrica cerebral (Figuras 7 e 8), tivemos a certeza de que a resposta estava no SNC. Agora, olhando retrospectivamente, podemos perceber que as modificações no SNC provocadas pelo Cloridrato de Cetamina ou pela introdução de eletrodos poderiam modificar a resposta uterina, constituindo interferências na nossa investigação.

Por sorte tivemos a felicidade de conhecer em 1995 o professor Bjorn NORDENSTRÖM.

O professor NORDENSTRÖM é o autor da teoria dos CEBF, já descrita na revisão da literatura. Estudando a teoria dos CEBF, concluímos 
que o estímulo elétrico poderia chegar ao útero por vias diferentes das nervosas.

Com a sugestão do professor Cesar Timo-Iaria realizamos as lesões medulares na altura de T1, mas a AEU continuou aumentando após a eletroacupuntura (Tabela 4, experimentos 1 e 2). Era a prova de que o SNC não tinha relação com o aumento da AEU pós-eletroacupuntura, embora não possamos descartar a possibilidade de que exista uma ligação entre SNC e Útero ( Figuras 7 e 8). Nesse caso, o SNC faria o papel modulador.

Mas ainda restava o sistema nervoso periférico (SNP). Por sugestão do professor César Timo-Iaria, procedemos à alcoolização dos nervos uterinos com álcool absoluto. Mais uma vez esse procedimento não alterou o aumento da AEU pós-eletroacupuntura (Tabela 4, experimentos 3 e 4). Ainda realizamos o experimento estimulando a região da carótida, sem modificar o resultado (Tabela 4, experimento 9). Por sugestão do professor Edécio Armbruster isolamos a artéria do rabo da rata e realizamos dois experimentos, verificando que após o clampeamento da artéria o sinal elétrico provocado pelo eletroestimulador desaparecia do útero. Portanto, mesmo sem sistema nervoso atuante, o sinal elétrico continua a chegar no útero, provocando o aumento da AEU. Nossos dados apontam para a transmissão elétrica através do sangue.

Os trabalhos de NORDENSTRÖM esclarecem essa dúvida. O experimento mais elucidativo dentre os que ajudaram a identificar os $\mathrm{CEBF}$ foi o realizado em cachorros, onde uma corrente contínua de lesão foi 
passada entre o catodo (polo negativo) localizado na aorta e o anodo (polo positivo) no mesentério. Após a passagem da corrente, NORDENSTRÖM observou que a artéria tornava-se marrom e trombosada, enquanto que as outras estruturas ficavam razoavelmente preservadas. Esse experimento mostra que a corrente elétrica transita preferencialmente pela via arterial (Figura 1) (NORDENSTRÖM, 1983).

Decidimos então reproduzir os experimentos in vitro, retirando o útero da rata e fazendo um modelo de CEBF (Figura 6). O aumento da AEU após a estimulação elétrica no CEBF estabelece um modelo do que observamos in vivo.

$\mathrm{O}$ experimento onde denervamos o útero e estimulamos a carótida serve apenas como um guia (ou como modelo), já que é um experimento único. Mas o fato de ao estimularmos a carótida, longe de qualquer ponto de acupuntura, aumentar a AEU corrobora com os outros achados, principalmente aliado aos experimentos no rabo dos animais (Figura 10).

Mas o fato de o estímulo elétrico nos pontos de acupuntura alcançar o útero através do $\mathrm{CEBF}$ e não através do $\mathrm{SNC}$ leva-nos a mudanças conceituais importantes, quer no estudo da acupuntura, quer no estudo da fisiologia.

As mudanças nos rumos do estudo da acupuntura são claras: fica patente a necessidade do estudo dos CEBF pelos acupuntores. Os estudos 
envolvendo o SNC são limitados e não vão responder a todas as perguntas (como não responderam às nossas).

Quanto á fisiologia, estamos nos deparando com funções do sistema circulatório praticamente não investigadas em nosso meio. Estamos envolvidos por eletricidade e ondas eletromagnéticas (ressonância de Schumann, raios cósmicos, radiação da terra, aparelhos de televisão, camas elétricas, cobertores térmicos, sistemas de alta tensão, monitores de computadores, aparelhos de telefonia celular, fornos de microondas, aparelhos hospitalares, unidades de terapia intensiva, só para citar alguns). Qual o papel dos CEBF na saúde e na doença? Acreditamos ser urgente a pesquisa nessa área.

Mesmo dentro da nossa investigação, ainda sobram muitas dúvidas. Sabemos que o estímulo elétrico chega ao útero por via não nervosa, provavelmente vascular. Mas o estímulo que ministramos é de $15 \mathrm{~Hz}$ (ou seja, 15 pulsos por segundo), muito diferente do aumento da AEU, que é de cerca de 26 pulsos cada 3 minutos em média, ou seja, na freqüência de 0,14 $\mathrm{Hz}$.

Com base na literatura, podemos especular o que acontece. Sabemos que para obtermos a contração uterina, temos que aumentar a concentração de íons calcio, $\left[\mathrm{Ca}^{+2}\right]$, de $10^{-7}$ para $10^{-5}$ molar (KAMM; STULL, 1989). E que o $\mathrm{Ca}^{+2}$ entra na célula endometrial através de alterações elétricas provocadas pelos agonistas, como o $\mathrm{IP}_{3}$ e o AMPc, através de canais voltagem dependentes (VGC) (VAN BREEMEN; SAIDA, 1989). Então a 
eletroacupuntura a $15 \mathrm{~Hz}$ pode estar mimetizando as alterações elétricas da membrana da célula miometrial, permitindo que o $\mathrm{Ca}^{+2}$ entre nas células, possibilitando as contrações.

Outras possibilidades são que as alterações elétricas provocadas pela eletroacupuntura modifiquem o metabolismo celular miometrial ou no endotélio dos vasos sangüíneos, já que parece que essa via é preferencial no transporte da energia elétrica ao útero. As possibilidades são alterações dos agonistas do $\mathrm{Ca}^{+2}$, como o IP3, GMPc ou AMPc, ou aumento das prostaglandinas $\mathrm{E}_{2}$ e $\mathrm{F}_{2 \alpha}$, seja no miométrio ou nos vasos sangüíneos. Infelizmente a literatura é controversa e não permite conclusões, principalmente porque a maioria dos experimentos envolvem o SNC, o que não é o nosso caso.

Portanto, o estímulo da eletroacupuntura é transportado do ponto de acupuntura até o útero de ratas Wistar pelo sistema circulatório, gerando alterações elétricas na membrana do músculo liso uterino, gerando despolarizações. As alterações nos canais de $\mathrm{Ca}^{+2}$ e nos agonistas das contrações uterinas merecem investigações futuras. 
CONCLUSÕES 
1. a AEUR é semelhante em ratas Wistar prenhes e não prenhes;

2. a eletroacupuntura aplicada nos pontos Sanyinjiao (BP 6) e Zusanli (E 36), com a freqüência de $15 \mathrm{~Hz}$ e intensidade suficiente para provocar contrações musculares no local, aumenta a AEU em ratas Wistar entre 17 e 19 dias de prenhez;

3. o Sistema Nervoso não é necessário para o aumento da AEU;

4. nossos resultados sugerem fortemente que a energia elétrica alcança o miométrio através dos CEBF. 
REFERÊNCIAS BIBLIOGRÁFICAS 
BAUER-DANTOIN, A. C.; KNOX, K. L.; SCHWARTZ, N. B.; LEVINE, J. E. Estrous cycle stage-dependent effects of neuropeptide-Y on luteinizing hormone (LH)-releasing hormone-stimulated $\mathrm{LH}$ and follicle-stimulating hormone secretion from anterior pituitary fragments in vitro. Endocrinology, v. 133, n. 6, p. 2413-7, 1993.

BUCINSKAITE, V.; LUNDERBERG, T.; STENFORS, C.; EKBLOM, A., DAHLIN, L., THEODORSSON, E. Effects of electroacupuncture and physical exercise on regional concentratikons of neuropeptides in rat brain. Brain Res., v. 666, p. 128-32, 1994.

BUCINSKAITE, V.; THEODORSSON, E.; CRUMPTON, K.; STENFORS, C.; EKBLOM, A.; LUNDEBERG, T. Effects of repeated sensory stimulation (electro-acupuncture) and physical exercise (running) on open-field behaviour and concentrations of neuropeptides in the hippocampus in WKY and SHR rats. Eur. J. Neurosci., v. 8, n. 2, p. 382-7, 1996.

CAI, W. Acupuncture and Nervous Sistem. Am. J. Chin. Med., v. 20, n. 34, p. 331-7, 1992.

CARRARA, W. Maturação do colo uterino com o emprego intracervical da prostaglandina "F2 alpha" na indução do trabalho de parto. São Paulo, 1990, Tese (Doutorado), Faculdade de Medicina, Universidade de São Paulo.

CHENG, B.; PAN, C.; ZHU, S.; ZHANG, H.; SUN, D.; QIN, L.; HAN, C. Preliminary observation on the correlation between the difference of plasma cAMP levels before and after induction and the effectiveness of acupuncture anesthesia. In: Advances in Acupuncture and Acupuncture Anaesthesia, Beijing, The People's Medical Publishing House, 1979, p. 468-9.

CISZEK, M.;SZOPINSKI, J.; SKIZYPULEC, V. Investigations on morphological structure of acupuncture points and meridians. J. Trad. Chin. Med., v. 5, n. 4, p. 289-92, 1985. 
COHEN, M.; KWOK, G.; COSIC, I. Acupuncture needles and the seebeck effect. Do temperature gradients produce electrostimulation. Acupunct. Electro-therapeut. Res., v. 22, n. 1, p. 9-15, 1997.

COLMERS, W.F.; BLEAKMAN, D. Effects of neuropeptide Y on the electrical properties of neurons. TINS, v. 17, n. 9, p. 373-9, 1994.

CONSELHO FEDERAL DE MEDICINA, Resolução 1455, 11 de agosto de 1995.

FAIRLIE, F. M.; LANG, G. K.; GREER, I. A.; McLAREN, M. Umbilical artery doppler flow velocity waveforms and maternal prostaglandin $\mathrm{E}_{2}$ and $\mathrm{F}_{2 \alpha}$ metabolite concentration during cervical ripening with prostaglandin E2. Eur. J. Obst. Gynecol., v. 37, p. 7-13, 1990.

FANG, J. The influence of acpuncture at zusanli on cyclic nucleotide contents of plasma, different brain regions and spleen in rats. Chen Tzu Yen Chiu,v. 19, n. 1, p. 42-5, 1994. [Resumo em Medline, online, HealthGate: http://www.healthgate.com/]

FARBER, P. L. A Medicina do século XXI - A união definitiva entre a medicina ocidental e a oriental. São Paulo, Roca, 1997. 183p.

FARBER, P. L.; CARRARA, W.; DZIK, A. E ZUGAIB, M. Indução do trabalho de parto por estimulação elétrica nos pontos de acupuntura. Anais do Congresso Brasileiro de Ginecologia e Obstetrícia, Palácio das Convenções do Anhembi, São Paulo, 1989.

FARBER, P. L.; CARRARA, W.; DZIK, A. E ZUGAIB, M. Indução do trabalho de parto por estimulação elétrica sobre pontos de acupuntura. Rev. Gin. Obst. Bras., v. 5, n. 2, p. 81-5, 1994.

FARBER, P. L.; TIMO-IARIA, C. Acupuntura e Sistema Nervoso. J. B. M., v. 67, p. 126-31, 1994.

FLECK, H. Acupuncture and Neurophisiology. Bull. N. Y. Acad. Med., v. 51, n. 8, p. 903-13, 1975. 
GUYTON, Anatomia funcional e contração do músculo.In: GUYTON, Fisiologia Humana, 6. Ed. p. 78-95, 1988.

HEINE, H. Anatomical structure of acupoints. J. Trad. Chin. Med., v. 8, n. 3, p. 207-12, 1988.

HUGHES, J.; SMITH, T. W.; KOSTERLITZ, H. W., FOTHERGILL, L. A.; MORGAN, B. A.; MORRIS, H. R. Identification of two related pentapeptides from the brain with potent opiate agonist activity. Nature (Lond.). v. 258, p. 577-9, 1975.

HYVARINEN, J.; KARLSON, M. Low resistance skin points that may coincide with acupuncture loci. Med. Biol., v. 55, p. 88-94, 1977.

JIANREN, M.; WEIPING, Y.; QIZHANG, Y. Electrical stimulation of Hypothalamic Arcuate Nucleus can change response to electroacupuncture of Dorsal Raphe Nucleus and Locus Coeruleus. J. Trad. Chin. Med., v. 7, n. 3, p. 215-20, 1987.

KAMM, K. E. ; STULL, J. T. The function of myosin light chain kinase phosphorilation in smooth muscle. Ann. Rev. Pharmacol. Toxicol., v. 25, p. 593-620, 1985.

KAMM, K. E.; STULL, J. T. Regulation of smooth muscle contractile elements by second messengers. Ann. Rev. Physiol., v. 51, p. 299-313, 1989.

KELLY, R. Pregnancy maintenance and parturition: The role fo prostaglandin in manipulating the immune and inflamatory response. Endocrine Rev., v. 15, n. 5, p. 684-703, 1994.

KISHIOKA, S.; MIYAMOTO, Y.; FUKUNAGA, Y.; NISHIDA, S.; YAMAMOTO, $\mathrm{H}$. Effects of a mixture of peptidase inhibitors (amastatin, captopril and phosphoramidon) on Met-enkephalin-, betaendorphin-, dynorphin-(1-13)- and electroacupuncture-induced antinociception in rats. Jpn. J. Pharmacol., v. 66, n. 3, p. 337-45, 1994 
KUBISTA, E.; KUCERA, H.; MULLER, T. Y. L. Initiating contraction of the gravid uterus through electro-acupuncture. Am. J. Chin. Med., v. 3, n. 4, p. 343, 1975.

LEE, J-H.; BEITZ, A. J. Electroacupuncture modifies the expression of cFos in the spinal cord induced by noxious stimulation. Brain Res., v. 577, p. 80-91, 1992

LEE, J-H.; BEITZ, A. J. The distribution of brain- stem and spinal cord nuclei associated with different frequencies of electroacupuncture analgesia. Pain, v. 52, p. 11-28, 1993

LEVY, B.; MATSUMOTO, T. Patophysiology of acupuncture: nervous sistem transmition. Am. Surg.; p. 378-84, June 1975

LI, C.; BI, L.; ZHU, B.; QI, M.; ZHAO, C.; YAO, Z.; LU, Z.;SUN, S.; DONG, H. Effects of acupuncture on left ventricular function, microcirculation, cAMP and cGMP of acute myocardial infarction patients. J. Trad. Chin. Med., v. 6, n. 3, p. 157-61, 1986.

MANABE, Y.; YOSHIMURA, S.; MORI, T.; ASO, T. Plasma levels of 13,14-dihidro-15-keto prostaglandin $\mathrm{F}_{2 \alpha}$, estrogens e progesterone during stretch-induced labor at term. Prostaglandins, v. 30, n. 1, p. $141-52,1985$.

MANABE, Y.; SAGAWA, N.; MORI, T. Fetal viability does not affect the onset of stretch-induced labor and the increase in amniotic fluid prostaglandin $F_{2 \alpha}$ and plasma prostaglandin $F_{2 \alpha}$ metabolite levels. Prostaglandins, v. 44, p. 119-28, 1992.

MAZOR, M.; WIZNITZER, E.; MAYMON, E.; LEIBERMAN, J. R.; COHEN, A. Changes in amniotic fluid concentrations of prostaglandins $\mathrm{E}_{2}$ e $\mathrm{F}_{2 \alpha}$ in women with preterm labor. Isr. J. Med. Sci., v. 26, n. 8, p. 425-8, 1990.

MIAO, W.; GUO, Y.; ZHANG, Y.; XU, T.; ZHANG, C. The influence of changing the $\mathrm{Ca} 2+$ concentration of the point quze (PC3) on the curative effect of puncturing neiguan (PC6) in experimental arrhythmnic rabbits. Chen Tzu Yen Chiu, v. 18, n. 3, p. 243, 1993. 
[Resumo em Medline, on-line, HealthGate: http://www.healthgate.com/]

NOORT, W. A.; van BULK, B.; VEREECKEN, A.; de ZWART, F. A., KEIRSE, M. J. N. C. Changes in plasma levels of $P G F_{2 \alpha} P_{2}$ metabolites at and after delivery at term. Prostaglandins, v. 37, n. 1, p. 3-12, 1989.

NORDENSTRÖM, B. E. W. Biologically closed electric circuits. Stockholm, Nordic Medical publication, 1983. 358 p.

NORDENSTRÖM, B. E. W. The paradigm of biologically closed electric circuits (BCEC) and the formation of na international association (IABC) for BCEC systems. Eur. J. Surg., p. 7-23, 1994. Supplement 574.

PAXINOS, J.; WATSON, C.. The rat brain in stereotaxic coordinates. Academic Press, Sydney, 1982.

POMERANZ, B.; WARMA, N. Supression of noxious responses in single neurons of cat spinal cord by elecroacupuncture and reversable the opiate agonist naloxone. Exp. Neurol., v. 64, p. 327-41, 1979.

SATO, T.; TAKESHIGE, C.; SHIMIZU, S. Morphine Analgesia mediated by activation of the acupuncture-analgesia-producing system. Acupunct. Electrother. Res., v. 16, p. 13-26, 1991.

SJOLUND, B., TERENIUS, L.; ERIKSON, M. Increased cerebrospinal fluid levels of endorphins after electro-acupuncture. Acta Physiol. Scand., v. 100, p. 382-4, 1977.

SODIPO, J. O. A.; GILLY, H.; PAUSER, G. Endorphins: mechanism of acupuncture analgesia. Am. J. Chin. Med., v. 9, n. 3, p. 249-58, 1981.

TABB, T. N.; GARFIELD, R. E. Molecular biology of uterine contractility. Clin. Obst. Gynecol., v. 35 p. 494-504, 1992.

TAKESHIGE, C.; OKA, K.; MIZUNO, T.; HISAMITSU, T.; LUO, C., KOBORI, M.; MERA, H.; FANG, T. The acupuncture and its 
connecting central pathway for producing acupuncture analgesia. Brain Res. Bull., v. 30, p. 53-67, 1993.

TAKESHIGE, C.; SATO, T.; MERA, H.; HISAMITSU, T.; FANG, J. Descending pain inhibitory system involved in acupuncture analgesia. Brain Res. Bull., v. 29, p. 617-34, 1992.

TAKESHIGE, C.; TSUCHIYA, M.; GUO, S-Y.; SATO, T. Dopaminergic transmission in the hypothalamic arcuate nucleus to produce acupuncture analgesia in correlation with the pituitary gland. Brain Res. Bull., v. 26, p. 113-22, 1991 b.

TAKESHIGE, C.; ZHAO, W-H.; GUO, S-Y. Convergence from the Preoptic area and arcuate nucleus to the median eminence in acupuncture and nonacupuncture point stimulation analgesia. Brain Res. Bull., v. 26, p. 771-8, 1991a.

TODA, K.; IRIKI, A. Effects of electroacupuncture on thalamic evoked responses recorded from the ventrobasal complex and posterior nuclear group after tooth pulp stimulation in rat. Exper. Neurol., v. 66, p. 41922, 1979.

TSUEI, J. J.; YIU, F. L.; SHARMA, S. D. The influence of acupuncture stimulation during pregnancy. Obstet. Gynecol., v. 50, n. 4, p. 479, 1977.

VAN BREEMEN, C.; SAIDA, K. Cellular mechanism regulating $\left[\mathrm{Ca}^{2+}\right]_{\mathrm{I}}$ smooth muscle. Ann. Ver. Physiol ., v. 51 p. 315-29, 1989.

WANG, Q.; MAO, L. M.; HAN., J. S. The role of periaquedutal gray in mediation of analgesia produced by different frequencies electroacupuncture stimulation in rats. Int. J. Neurosci., v. 53, p.16772, 1990a. 
WANG. Q.; MAO, L. M.; HAN, J. S. The arcuate nucleus of hypothalamus mediate low but not high frequency electroacupuncture analgesia in rats. Brain Res, v. 513, p. 60-6, 1990 b.

WOLFS, G. M. J. A. ; LEEUWEN, M. Electromyografic observations on the human uterus during labour. Acta Obtetr. Gynecol. Scand., 1979. Supplement 90.

WRAY, S. Uterine contraction and physiological mechanisms of modulation. Am. J. Physiol., v. 264, p. C1-C18, 1993.

XU, S.; LI, W.; SHENG, M.; ZENG, D.; ZHANG, L. The cyclic 3', 5'adenosine monophosphate level in caudate perfusate during acupuncture analgesia. In: Advances in Acupuncture and Acupuncture Anaesthesia, Beijing, The people's Medical Publishing House, 1979, p. 469.

YIP, S. P.; PANG, J. C. K.; SUNG, M. L. Induction on labor by acupuncture electro-stimulation. Am. J. Chin. Med., v. 4, n. 3, p. 257, 1976.

ZANELlA, R. S. Agulha eletrodiatérmica. I Simpósio Brasileiro de Acupuntura Científica, São Paulo, 1989.

ZHANG, Y.; GUO, Y.; WANG, X.; SHI, L.; MIAO, W.; XU, T.; ZHANG, C. Influence of changing $\mathrm{Ca}++$ concentration in neiguan $\left(\mathrm{PC}^{\wedge}\right)$ on the effect of acupuncture treating experimental arrhytmia of rabbits. Chen Tzu Yen Chiu, v. 20, n. 2, p. 63-7, 1995. [Resumo em Medline, online, HealthGate: http://www.healthgate.com/]

ZHENGQIU. C.; WEI, X.; YU, L. Identification of cortico-thalamic neurons: involvemente of cortical descending modulation in acupuncture analgesia. J. Trad, Chin, Med., v. 6, n. 3, p. 189-200, 1986

ZHOU, L.; CHEN, Y. Changes in plasma PGE concerntration among patients under acupuncture anesthesia. In: Advances in Acupuncture and Acupuncture Anaesthesia, Beijing, The People's Medical Publishing house, 1979, p. 497-8. 
ZHOU, Y. H; SUN, Y. H.; SHEN, J. M.; HAN, J. S.. Increased release of immunoreactive CCK-8 by electroacuuncture and enhancement of electroacupuncure by CCK-B agonist in rat spinal cord. Neuropeptides, v. 24, p. 139-44, 1993.

ZHU, R.; KAO, X., ZHOU, Y.; YU, J. The induction on labor by electroacupuncture stimulation: an analysis of 771 cases. In: Research on acupuncture, moxibustion and acupuncture anesthesia, Beijing, Science Press, 1986, p. 930-7. 